\title{
Model-Based Fault Detection and Isolation of a Liquid-Cooled Frequency Converter on a Wind Turbine
}

\author{
Peng Li, ${ }^{1}$ Peter Fogh Odgaard, ${ }^{1}$ Jakob Stoustrup, ${ }^{2}$ Alexander Larsen, ${ }^{2}$ and Kim Mørk ${ }^{2}$ \\ ${ }^{1}$ Innovation Center, KK-Electronic a/s, Bøgildvej 3, 7430 Ikast, Denmark \\ ${ }^{2}$ Section of Automation and Control, Department of Electronic Systems, Aalborg University, Fredrik Bajers Vej 7C, \\ 9220 Aalborg, Denmark
}

Correspondence should be addressed to Peter Fogh Odgaard, peodg@kk-electronic.com

Received 11 April 2011; Revised 20 November 2011; Accepted 1 December 2011

Academic Editor: Ricardo Dunia

Copyright (C) 2012 Peng Li et al. This is an open access article distributed under the Creative Commons Attribution License, which permits unrestricted use, distribution, and reproduction in any medium, provided the original work is properly cited.

\begin{abstract}
With the rapid development of wind energy technologies and growth of installed wind turbine capacity in the world, the reliability of the wind turbine becomes an important issue for wind turbine manufactures, owners, and operators. The reliability of the wind turbine can be improved by implementing advanced fault detection and isolation schemes. In this paper, an observer-based fault detection and isolation method for the cooling system in a liquid-cooled frequency converter on a wind turbine which is built up in a scalar version in the laboratory is presented. A dynamic model of the scale cooling system is derived based on energy balance equation. A fault analysis is conducted to determine the severity and occurrence rate of possible component faults and their end effects in the cooling system. A method using unknown input observer is developed in order to detect and isolate the faults based on the developed dynamical model. The designed fault detection and isolation algorithm is applied on a set of measured experiment data in which different faults are artificially introduced to the scaled cooling system. The experimental results conclude that the different faults are successfully detected and isolated.
\end{abstract}

\section{Introduction}

Wind energy is one of the world's fastest growing renewable energy forms. According to the Global Wind Energy Council (GWEC) report [1], 2009 had the highest installation of wind power with more than $38 \mathrm{GW}$ of power added which reaches an annual growth of $31.7 \%$. This brings the cumulative installation capacity of wind power to more than $158.5 \mathrm{GW}$. Wind energy, therefore, contributes significantly to the world's power production. In the same time, new technologies and designs are being incorporated in the contemporary wind turbines. The power level of the wind turbine has increased from kilowatt $(\mathrm{kW})$ level to megawatt (MW) level since last two decades. Today, the wind turbines contain a variety of complex systems, and they needed to be shut down due to failure or malfunction of a minor component. The maintenance personnel has to take an unscheduled maintenance for repairing or replacing the failure component. Consequently, the operation and maintenance $(\mathrm{O} \& \mathrm{M})$ costs of the wind turbines will increase significantly due to the unscheduled maintenance. In order to reduce O\&M costs, improve the reliability of the wind turbines, and avoid unscheduled maintenance, advanced fault detection and accommodation schemes will be taken into account to applying for the critical components in the wind turbines.

Some research works have been performed on fault detection, isolation and accommodation for wind turbines, in [2] an observer-based scheme for detecting different sensor faults in pitch system was described. An unknown input observer was designed for the purpose of detecting sensor faults for the drive train in wind turbines as presented in [3]. A benchmark model was proposed for implementing fault tolerant control to wind turbines in [4]. For doubly fed induction generator (DFIG), a current sensor fault detection and reconfiguration scheme was described in [5], and, in order to detect voltage sensor fault, a fault detection and reconfiguration scheme was presented in [6]. For detecting different kinds of faults in power converter in wind turbines, a field-programmable gate array (FPGA)-based real-time 
fault diagnosis scheme to power converter was proposed in [7], a fault tolerant control strategy for active power filter in power electronic converter was designed in [8].

In order to control output power quality of wind turbines, perform reactive power compensation to wind turbine generator, and smooth grid connection of wind power, frequency converters are used on the most of the contemporary MW class wind turbines. For wind turbines equipped with frequency converter, one of the key components in the frequency converter is the power module, which is composed of power semiconductor devices, for example, insulated gate bipolar transistors (IGBT). The power dissipation of these kinds of power semiconductor devices will increase significantly with the increase of their temperature. Therefore, power module cooling becomes an important issue of frequency converters in wind turbines. For cooling the power module, two approaches are currently used: liquid-cooling and air cooling. Based on the comparison of these two kinds of cooling solutions, liquid-cooling can be a preferable cooling system solution for frequency converters, since it results in a more controllable system, can increase placement flexibility and obtain a higher efficiency, and is insensitive to environment. However, liquid-cooled frequency converters are more sensitive to components faults in the cooling system and complex in their design. Consequently, the reliability of the cooling system in liquid-cooled frequency converter becomes an important issue for implementing this kind of frequency converter.

As have been investigated, there is no research works that have been focused on fault detection for cooling system in liquid-cooled frequency converter on wind turbine, but the several research projects about applying fault detection on similar applications have been carried out, for example, refrigeration system: in [9], an expert system was designed for a fault detection and diagnosis system of refrigeration process in a hydraulic power plant. In order to detect different components faults in commercial coolers and freezers, a decoupling-based fault detection and diagnosis method was presented in [10]. An online failure diagnosis system for compression refrigeration plants was developed in [11]. An online sensor-fault detection, diagnosis, and estimation strategy for centrifugal chiller systems was described in [12]. In order to detect faults in centrifugal chiller systems, a model-based online fault detection and diagnosis strategy was developed in [13].

From the present industrial application is known that, in the current manufactured liquid-cooled frequency converters, the implemented fault detection and accommodation schemes for cooling system are most often conservative. Therefore, a potential realistic solution of ensuring the high reliability of the cooling system in liquid-cooled frequency converter is to introduce advanced fault detection, isolation and accommodation methods. Through using advanced methods, wind turbines can reduce downtime and still produce power with a power limitation even though there are some faults in the wind turbines.

In this paper, an observer-based fault detection and isolation (FDI) scheme is designed for detecting and isolating faults in the cooling system in a liquid-cooled frequency converter on wind turbine application. The designed FDI scheme is mainly based on the principle of optimal unknown input observer which is an innovative application on liquidcooled frequency converter in wind turbine.

Lots of research on observer-based fault diagnosis have been carried out, including [14-20] for the last 20 years. In order to use observer-based fault diagnosis method, a mathematical model for the supervised system which can be used to represent dynamics performance of the system should be developed at first, and, subsequently, a fault residual will be generated by employing the developed model and measurement from the monitored system. Through using the developed accurate model of the system, the reliability and correctness of the FDI system can be achieved. However, in practice, the monitored system can be easily affected by disturbances and modelling errors. Considering the cooling system for the power module in the liquid-cooled frequency converter, it is found that the temperature of phase module in the power module can be affected by the ambient temperature. The ambient temperature is normally affected by different kinds of components which are placed in the nacelle of the wind turbine, such as generator, gearbox, and motors. Except for the ambient temperature, there also exists modelling errors when developing the mathematical model for the cooling system. The main causes of the modelling errors can be represented by two aspects. The first aspect is the thermodynamics performance of the cooling system. In order to develop the thermodynamic model of the cooling system, some necessary simplifications and ideal assumptions should be made. The second aspect is the nonlinearity of the cooling system. Linearization of the developed thermodynamic model is required when designing the FDI scheme. Therefore, in order to guarantee the robustness of the FDI scheme with respect to disturbances, the unknown input observer, which was shown by the research in [21, 22], can be considered as a solution to design a disturbance decoupled residual generator. For the modelling errors, they can be represented approximately as unknown disturbances which were already investigated by the research in $[23,24]$, so that the robustness of the FDI scheme with respect to the modelling errors can be guaranteed. However, besides of the modelling uncertainty (including both unknown disturbances and modeling errors), the system also suffers by noise. Consequently, an optimal unknown input observer, which can give disturbance decoupling minimum variance state estimation for noise and disturbances as stated in [25], will be used to design the FDI scheme for the cooling system.

The paper is organized as follows. Section 2 gives an overview of the liquid-cooled frequency converter test setup, a dynamic model is developed for the cooling system in the setup, and a fault analysis for the cooling system is presented. Section 3 presents a FDI algorithm for the cooling system, for which an optimal unknown input observer is designed. Section 4 describes the test experiments for the designed FDI algorithm, and conclusion and future works are stated in Section 5 . 


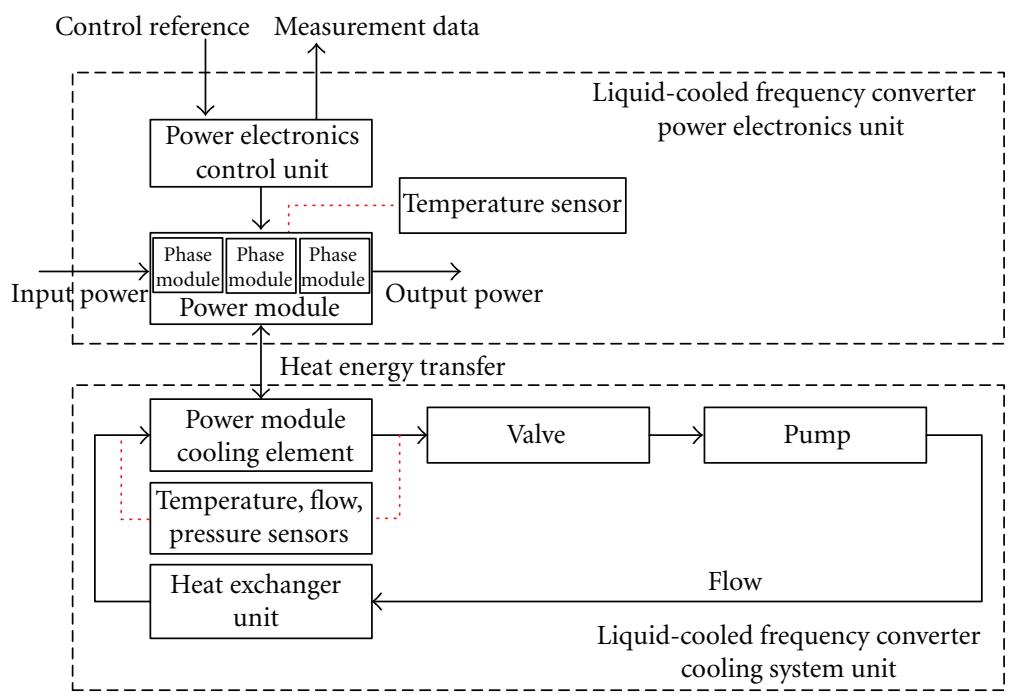

Figure 1: Configuration diagram of a liquid-cooled frequency converter for wind turbine application, red-dotted line is the connection between sensors and components.

\section{Problem Formulation}

2.1. System Description. The main components and structure of a liquid-cooled frequency converter used for wind turbines are shown as Figure 1. According to the functions of the main components in the liquid-cooled frequency converter, it can be divided into two parts: a power electronics unit and a cooling system unit, as shown in the dashed line zone in the figure.

From Figure 1, it is known that the power electronics unit is composed of a power electronics control unit, a power module and a number of temperature sensors. The power electronics control unit receives control reference to the power module from the wind turbine main controller and send back measurement data to the wind turbine main controller. The power module consists of a series of phase modules, which can be used to transfer input power into output power according to control demand from the power electronics control unit. The temperature of the phase module is measured by the temperature sensor. The cooling system unit in the liquid-cooled frequency converter consists of different components, including power module cooling element, valves, pump, heat exchanger unit, and sensors. The main function of the cooling system unit is to keep the temperature of the phase module in the power module under a given reference temperature value when the frequency converter is operating.

In order to simulate the entire liquid cooling system unit of a frequency converter, a scale test setup is built at Aalborg University, Denmark. The scale test setup in Aalborg University is shown as Figure 2. The test setup is composed of three parts, control computer, I/O unit, and cooling system. A PC with MATLAB and LabVIEW is used as control computer to control the cooling system in the test setup. National Instrument USB-6259 data acquisition board is selected as $\mathrm{I} / \mathrm{O}$ unit in order to collect data from sensors and control supply voltage to fan, pump, and power module. The configuration diagram of the cooling system in the test setup is shown as Figure 3. The cooling system contains different components, such as power module, aircooled heat exchanger, pump, valves, pipe and different kinds of sensors which include temperature sensor, flow meter and pressure sensor.

In the test setup, water is used as cooling liquid instead of a special liquid which is normally used in the liquid-cooled frequency converter. An air-cooled heat exchanger is used to refrigerate water and remove heat from the water which is generated by the power module. The supply voltage of the fan in the air-cooled heat exchanger can be controlled from 0 to 5 [V], as different rotation speed of the fan can be achieved. A centrifugal pump is used to circulate the water in the system. Two valves are installed, one valve is installed in front of the pump in the flow direction, which can be used to control the inlet flow to the pump, and another valve is installed after the pump, which can be used to control outlet flow from the pump to the air-cooled heat exchanger and the power module.

In order to measure the pressure, flow rate, and temperature in the test setup, a series of sensors is installed. The position of these sensors is shown in Figure 3. The function of these sensors is summarized in Table 1.

The temperature of inlet and outlet water for the power module is measured with temperature sensors which are installed at the inlet and outlet side of the pipe close to the power module. The temperature sensors measuring the temperature of phase modules are mounted in the middle of each phase module. The flow meter is used to measure the inlet flow rate of the power module. The pressure sensors are mounted at the inlet and outlet side of the power module in order to measure the pressure difference across the power module.

In the real liquid-cooled frequency converter, IGBT is used as phase module, however, in the test setup, in order 


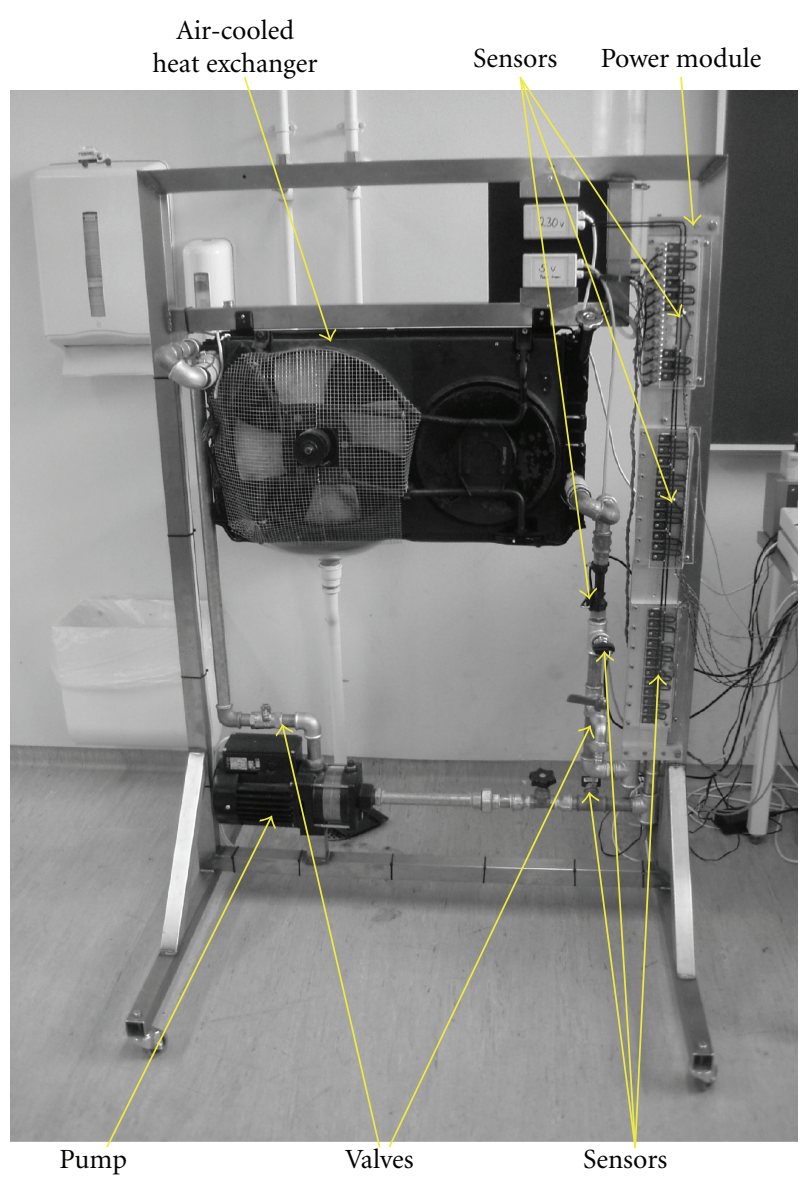

Figure 2: A scale test setup of liquid cooling system for a frequency converter in Aalborg University, Denmark.

to simulate the heat which is generated by the IGBT phase module, and resistors are used instead of the real IGBT phase module. The supply voltage to the power module can be controlled, so that the input power to the power module can be in the range from 0 to 1800 [W]. The configuration diagram of power module in the test setup is shown in Figure 4(a), and $P 1, P 2$ and $P 3$ represent the resistors which are used to simulate the IGBT phase module. From the view of direction A, shown as Figure 4(b), it is known that the power module consists of four components, phase module, aluminium plate, phase module cooling channel plate, and power module basement. These four components are integrated together as shown in the figure. The plots of these four components in the power module are shown as Figure 4(c). Figure 4(c.1) illustrates basement of the power module. There are inlet and outlet chambers in the basement. These two chambers are separated by a wall. By using this design, the cooling water can be forced to pass through phase module cooling channel plate, so that a good cooling effect can be provided to the phase module and aluminum plate. Figure 4(c.2) demonstrates the phase module cooling channel plate. It contains lots of small channels, through which cooling water can pass and be used to remove the heat on the aluminum plate. Figure 4(c.3) shows mounting structure of the phase module on the aluminum plate, and the resistors are mounted evenly as phase modules on the aluminum plate. The assemble sequence of these four components in power module is shown in Figure 4(c) as the numbered dashed line.

2.2. System Modeling. From the thermodynamics and working principle of the cooling system, it is known that there exists heat energy transfer phenomenon in the cooling system. According to Figures 1 and 3, it is known that the input power of phase module can be considered as the input heat energy of the cooling system. The temperature of phase module will vary due to different input power to the phase module. In order to remove the heat on the phase module which is caused by the input power, the phase module is cooled down by the water in the phase module cooling channel. Therefore, the temperature of cooling water in the phase module cooling channel will also be changed. The water that flows out from the power module will be circulated back to the power module by passing through a heat exchanger, where the water will be cooled down. Consequently, in order to describe the total thermodynamics performance in the cooling system unit, the following models should be developed: a model describing the dynamics of temperature variation of phase module due to the input power: a model representing the dynamics of power module outlet water temperature: a model describing the dynamics of power module inlet water temperature. The block diagram of the models that can be used to illustrate the thermodynamics performance in the cooling system unit can be shown as Figure 5.

The necessary simplifying assumptions for developing the dynamic model in the fault-free situation for the cooling system unit as follows:

(1) Temperature is an uniform temperature over the entire aluminum plate in the power module.

(2) Heat energy flow from phase module to ambient air can be omitted compared with heat energy flow to cooling water.

(3) Heat exchanging between cooling water, valves, pump, and pipe are omitted.

(4) Water in the system is incompressible.

(5) Water in power module outlet chamber is a well mixed of water from three phase module cooling channels.

(6) Each phase module has the equivalent surface area.

(7) The input power of power module is evenly distributed on the three phase modules $\left(P_{\text {in }}(t)=(1 / 3)\right.$. $\left.P_{\text {total }}(t)\right)$.

2.2.1. Model of Phase Module Temperature. From the view of thermal energy, the input power to the phase module in the liquid-cooled frequency converter can be considered as heat energy. This heat energy can be convected with the cooling water which flows through the phase module cooling channel under each phase module and the ambient air. According to 


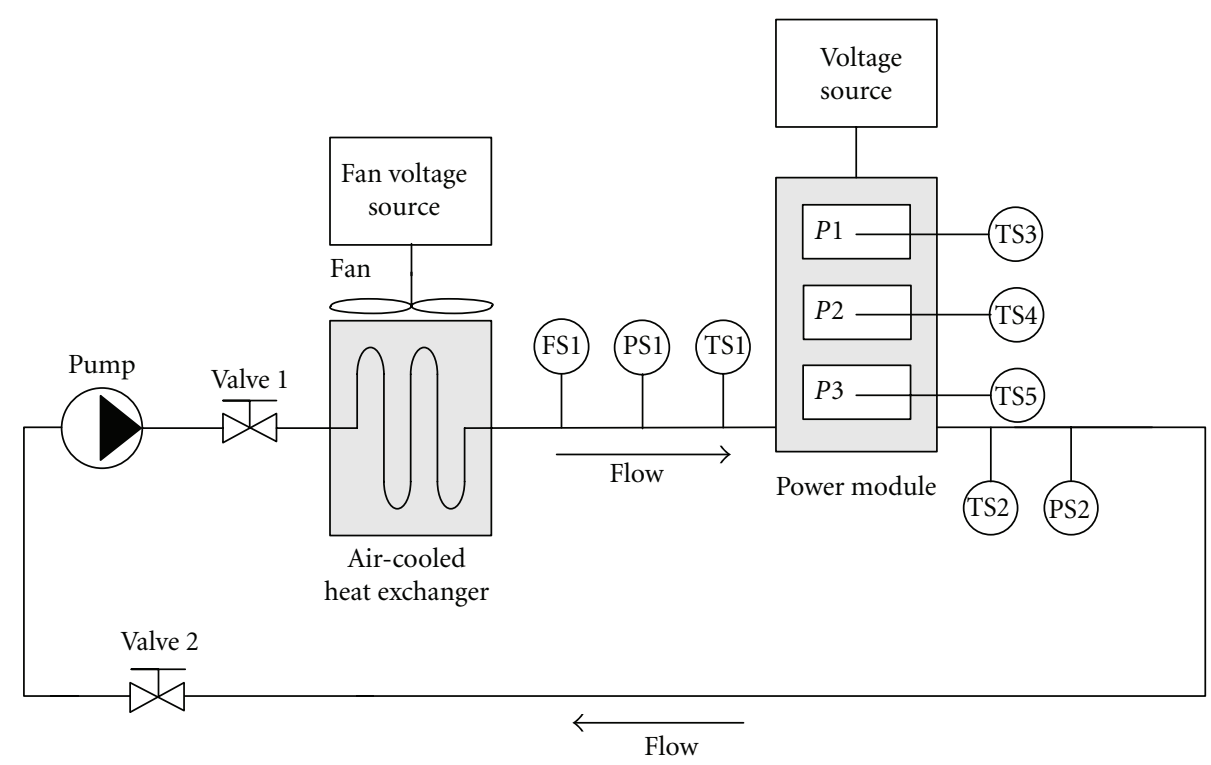

Figure 3: Configuration diagram of the cooling system in the test setup.

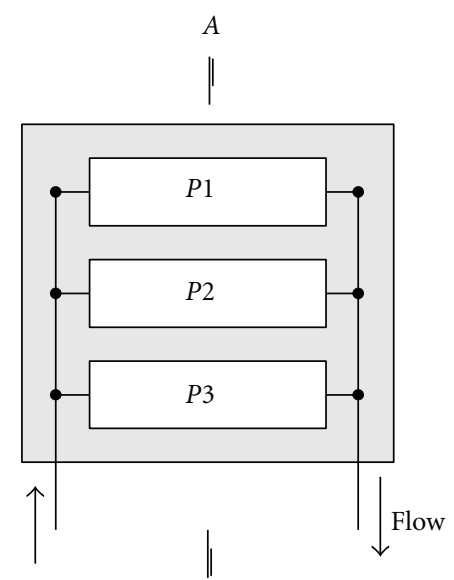

(a)

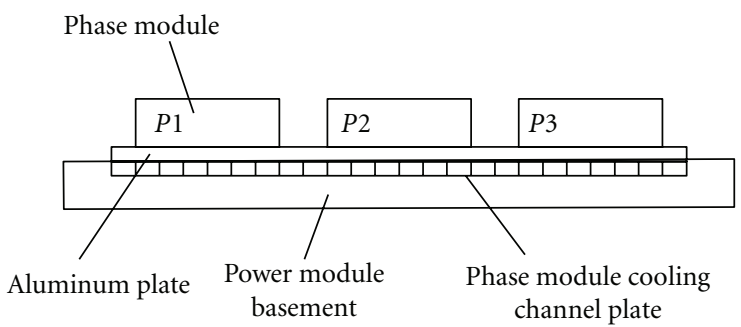

(b)

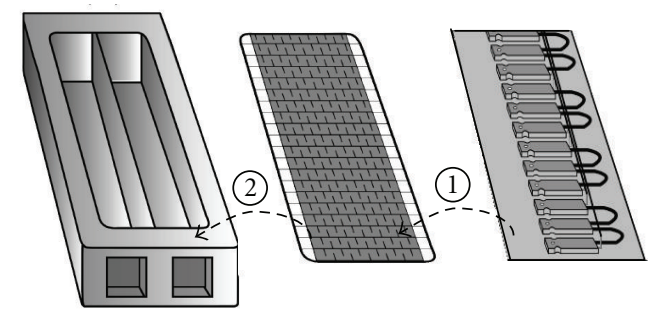

(c.1) (c.2)

(c)

FIgURE 4: Configuration diagram of the power module in the test setup.

the assumption, the convection between the phase module and the ambient air is neglected. The dynamic model of heat energy correlation between each phase module and the cooling water can be considered as

$$
\Delta \dot{E}_{\mathrm{pm}, i}=\dot{E}_{\mathrm{pm}, \mathrm{in}, i}-\dot{E}_{\mathrm{pm}, \text { out }, i} .
$$

According to the Newton's law in thermodynamics, the rate of heat loss for an object is proportional to the difference in temperatures between the object and its surroundings, therefore, the expression of the energy flow from phase module to the cooling water can be shown as

$$
\dot{E}_{\mathrm{pm}, \mathrm{out}, i}=h A_{\mathrm{pm}, i}\left(T_{\mathrm{pm}, i}(t)-T_{\mathrm{w}, i}(t)\right) .
$$

By using the relationship between the Nusselt's number, Reynold's number and Pradtl's number, as stated in [26], and combining the expression of these three numbers, the expression for $h$ in (2) can be obtained as:

$$
h=K_{\mathrm{h}} q^{0.8}
$$

where

$$
K_{\mathrm{h}}=0.023 \frac{\lambda \rho C^{0.3}}{A D} .
$$

By substituting (3) into (2), then (2) can be rewritten as

$$
\dot{E}_{\mathrm{pm}, \text { out }, i}=K_{\mathrm{h}} q^{0.8} A_{\mathrm{pm}, i}\left(T_{\mathrm{pm}, i}(t)-T_{\mathrm{w}, i}(t)\right) .
$$




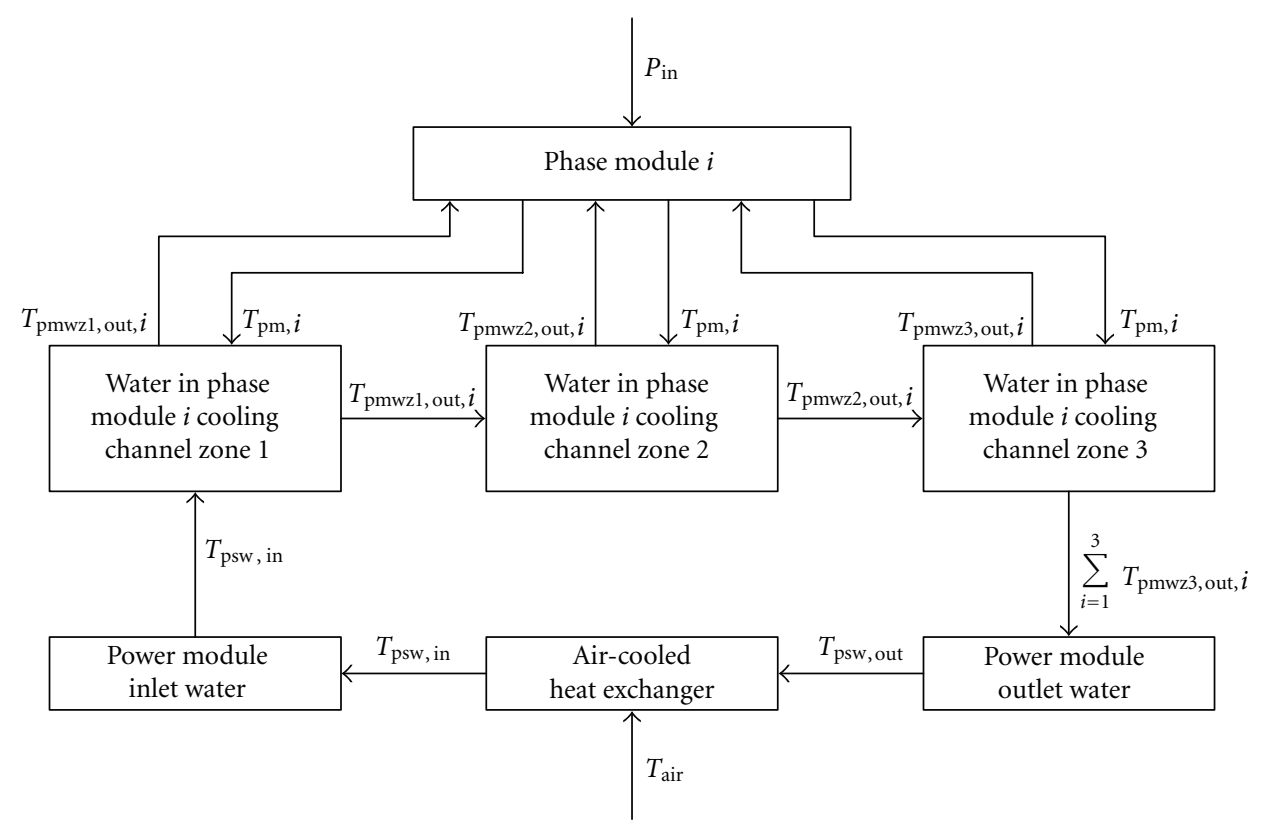

FIGURE 5: Block diagram of the models representing the thermodynamics performance in the cooling system test setup.

The dynamic model of heat energy flow from the phase module to the cooling water can be expressed as

$$
M_{\mathrm{pm}} \cdot c_{\mathrm{alu}} \cdot \dot{T}_{\mathrm{pm}, i}(t)=P_{\mathrm{in}}(t)-K_{\mathrm{h}} q^{0.8} A_{\mathrm{pm}, i}\left(T_{\mathrm{pm}, i}(t)-T_{\mathrm{w}, i}(t)\right) .
$$

By rearranging (6), the dynamic model of phase module temperature can be finally expressed as

$$
\dot{T}_{\mathrm{pm}, i}(t)=\frac{P_{\text {in }}(t)}{M_{\mathrm{pm}} \cdot c_{\mathrm{alu}}}-\frac{K_{\mathrm{h}} q^{0.8} A_{\mathrm{pm}, i}}{M_{\mathrm{pm}} \cdot c_{\mathrm{alu}}}\left(T_{\mathrm{pm}, i}(t)-T_{\mathrm{w}, i}(t)\right) .
$$

From the experiment, it is known that the water temperature in the phase module cooling channel will increase with the length from the inlet side to outlet side. Therefore, the cooling channel of each phase module can be divided into three zones horizontally and there exists heat transfer between each zone. In Figure 6, dashed line shows the zonal division for cooling channel of phase module 3: for cooling channel of phase module 1 and 2 , the same zonal division is used.

The water temperature $T_{\mathrm{w}, i}$ in (7) can be expressed as the mean of water temperature from three zones, which can be expressed as

$$
T_{\mathrm{w}, i}(t)=\frac{T_{\mathrm{pmwzl}, \mathrm{out}, i}(t)+T_{\mathrm{pmwz} 2, \mathrm{out}, i}(t)+T_{\mathrm{pmwz} 3, \text { out }, i}(t)}{3} .
$$

2.2.2. Model of Power Module Outlet Water Temperature. The dynamic model of power module outlet water temperature represents the dynamics of the water temperature in the power module outlet chamber. In order to derive this temperature model, the dynamic model of outlet water temperature for each phase module is considered at first.

The energy balance expression for the outlet water of each phase module can be shown as

$$
\begin{aligned}
M_{\mathrm{pmw}, \text { out }} & \cdot \mathcal{c}_{\mathrm{w}} \cdot \dot{T}_{\mathrm{pmw}, \text { out }}(t) \\
= & m_{\mathrm{pm}, \text { in }} \cdot c_{\mathrm{w}} \cdot T_{\mathrm{pmw}, \text { in }}(t) \\
& -m_{\mathrm{pm}, \text { out }} \cdot c_{\mathrm{w}} \cdot T_{\mathrm{pmw}, \text { out }}(t) \\
& +h A_{\mathrm{pm}, i}\left(T_{\mathrm{pm}, i}(t)-T_{\mathrm{pmw}, \text { out }}(t)\right) .
\end{aligned}
$$

Through inserting the expression of mass flow and (3), and rearranging (9), a general expression of outlet water temperature of each phase module can be expressed as

$$
\begin{aligned}
\dot{T}_{\text {pmw out }}(t)= & \frac{q \rho}{M_{\text {pmw,out }}}\left(T_{\text {pmw,in }}(t)-T_{\text {pmw out }}(t)\right) \\
& +\frac{K_{\mathrm{h}} q^{0.8} \cdot A_{\mathrm{pm}, i}}{M_{\mathrm{pmw}, \text { out }} \cdot c_{\mathrm{w}}}\left(T_{\mathrm{pm}, i}(t)-T_{\mathrm{pmw}, \text { out }}(t)\right) .
\end{aligned}
$$

Because the cooling channel for each phase module is divided into three zones, based on the expression (10), the 


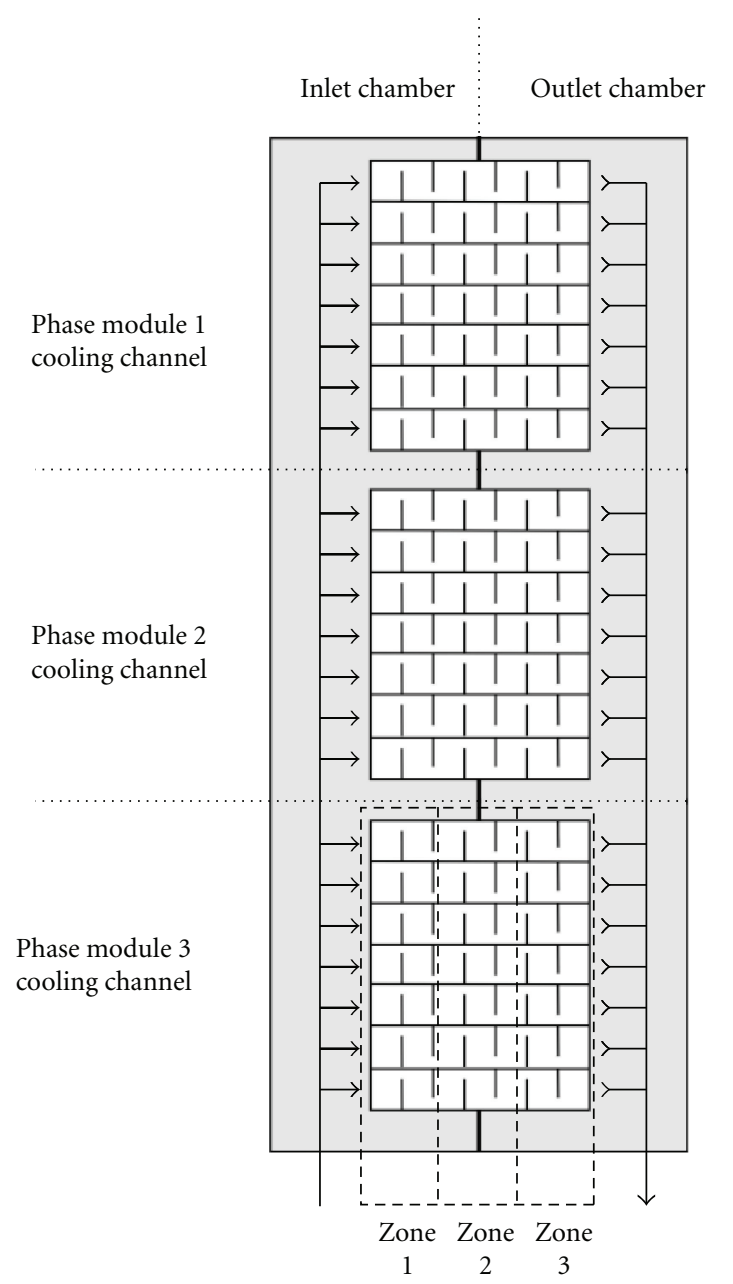

Figure 6: Illustration of zonal division of phase module cooling channel for phase module 3 in the power module, each phase module cooling channel is divided into three zones.

expression of cooling water temperature for each zone in each phase module cooling channel can be expressed as

$$
\begin{aligned}
\dot{T}_{\mathrm{pmwz} 1, \text { out }, i}(t)= & \frac{q \rho}{M_{\mathrm{pmwzl} 1, \text { out }}}\left(T_{\mathrm{psw}, \text { in }}(t)-T_{\mathrm{pmwz}, \text { out }, i}(t)\right) \\
& +\frac{K_{\mathrm{h}} q^{0.8} \cdot A_{1}}{M_{\mathrm{pmwz} 1, \text { out }} \cdot c_{\mathrm{w}}}\left(T_{\mathrm{pm}, i}(t)-T_{\mathrm{pmwz} 1, \text { out }, i}(t)\right),
\end{aligned}
$$

$$
\begin{aligned}
\dot{T}_{\mathrm{pmwz2}, \text { out }, i}(t)= & \frac{q \rho}{M_{\mathrm{pmwz2}, \text { out }}}\left(T_{\mathrm{pmwz} 1, \mathrm{out}, i}(t)-T_{\mathrm{pmwz2}, \text { out }, i}(t)\right) \\
& +\frac{K_{\mathrm{h}} q^{0.8} \cdot A_{2}}{M_{\mathrm{pmwz2}, \text { out }} \cdot c_{\mathrm{w}}}\left(T_{\mathrm{pm}, i}(t)-T_{\mathrm{pmwz2}, \text { out }, i}(t)\right),
\end{aligned}
$$

$$
\begin{aligned}
\dot{T}_{\mathrm{pmwz} 3, \text { out }, i}(t)= & \frac{q \rho}{M_{\mathrm{pmwz} 3, \text { out }}}\left(T_{\mathrm{pmwz2}, \text { out }, i}(t)-T_{\mathrm{pmwz} 3, \text { out }, i}(t)\right), \\
& +\frac{K_{\mathrm{h}} q^{0.8} \cdot A_{3}}{M_{\mathrm{pmwz}, \text { out }} \cdot c_{\mathrm{w}}}\left(T_{\mathrm{pm}, i}(t)-T_{\mathrm{pmwz}, \text { out }, i}(t)\right),
\end{aligned}
$$

TABLE 1: List of sensors in the test setup.

\begin{tabular}{ll}
\hline Symbol & Sensor function \\
\hline FS 1 & Flow sensor (inlet) \\
PS 1 & Pressure sensor (inlet) \\
PS 2 & Pressure sensor (outlet) \\
TS 1 & Temperature sensor (inlet) \\
TS 2 & Temperature sensor (outlet) \\
TS 3 & Temperature sensor (phase module 1 (P1)) \\
TS 4 & Temperature sensor (phase module 2 (P2)) \\
TS 5 & Temperature sensor (phase module 3 (P3)) \\
\hline
\end{tabular}

where

$$
\begin{gathered}
M_{\text {pmwz1,out }}=M_{\text {pmwz2,out }}=M_{\text {pmwz3,out }}=\frac{M_{\text {pmw,out }}}{3}, \\
A_{1}=A_{2}=A_{3}=\frac{A_{\mathrm{pm}, i}}{3} .
\end{gathered}
$$

As shown in Figure 6, it is known that the power module is composed of three phase modules, and according to the assumption, the water in the power module outlet chamber is a mixture of water from the three phase module cooling channel outlets therefore, the dynamic model of power module outlet water temperature can be expressed as

$$
\begin{aligned}
M_{\mathrm{psw}, \text { out }} \cdot c_{\mathrm{w}} \cdot \dot{T}_{\mathrm{psw}, \text { out }}(t)= & \sum_{i=1}^{3}\left(m_{\mathrm{ps}, \mathrm{in}, i} \cdot c_{\mathrm{w}} \cdot T_{\mathrm{pmwz} 3, \text { out }, i}(t)\right) \\
& -m_{\mathrm{ps,out}} \cdot c_{\mathrm{w}} \cdot T_{\mathrm{psw}, \text { out }}(t) .
\end{aligned}
$$

By inserting the expression of mass flow and rearranging the expression of (15), the expression for power module outlet water temperature can be expressed as

$\dot{T}_{\mathrm{psw}, \text { out }}(t)=\frac{q \rho}{M_{\mathrm{psw}, \text { out }}}\left(\left(\sum_{i=1}^{3} T_{\mathrm{pmwz}, \text { out }, i}(t)\right)-3 \cdot T_{\mathrm{psw}, \text { out }}(t)\right)$.

2.2.3. Model of Power Module Inlet Water Temperature. The power module inlet water temperature will be considered since it can be used to illustrate the heat energy dynamic performance of power module inlet water. In order to derive the dynamic model of power module inlet water temperature, the dynamic model of air-cooled heat exchanger will be considered first.

The energy balance of the air-cooled heat exchanger can be expressed as:

$$
\begin{aligned}
M_{\mathrm{W}} \cdot c_{\mathrm{W}} \cdot \dot{T}_{\text {fanw,out }}(t)= & m_{\text {fanw,in }} \cdot c_{\mathrm{W}} \cdot T_{\text {fanw,in }}(t) \\
& -m_{\text {fanw,out }} \cdot c_{\mathrm{w}} \cdot T_{\text {fanw,out }}(t) \\
& +\lambda \cdot A \cdot\left(T_{\text {air }}(t)-T_{\text {fanw,out }}(t)\right) .
\end{aligned}
$$

According to the assumption, the heat exchanging in pipe, valve and pump is omitted, therefore, the relationship 


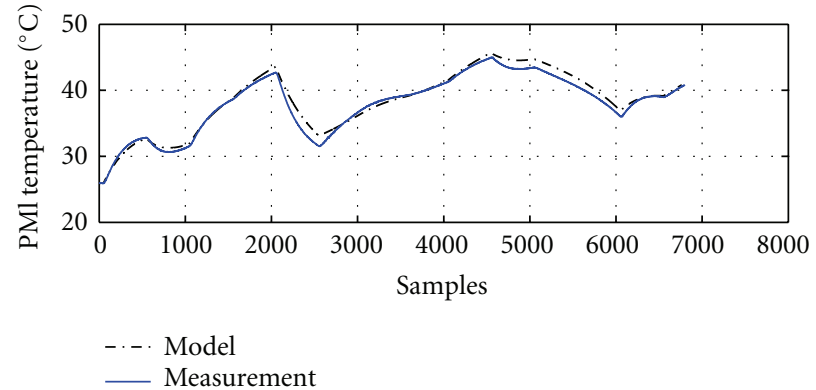

(a)

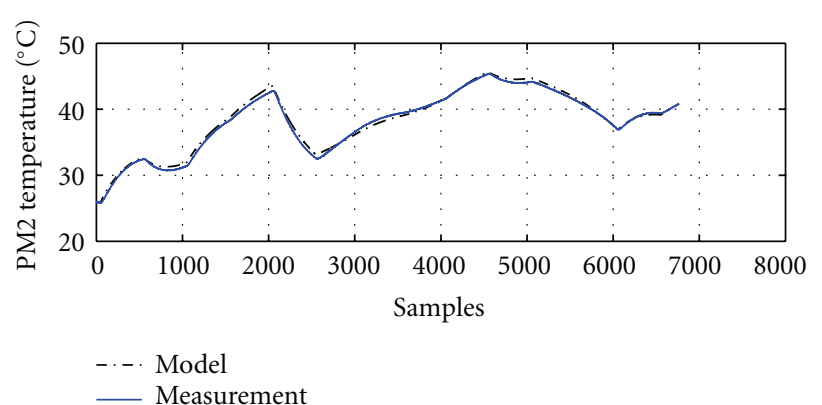

(b)

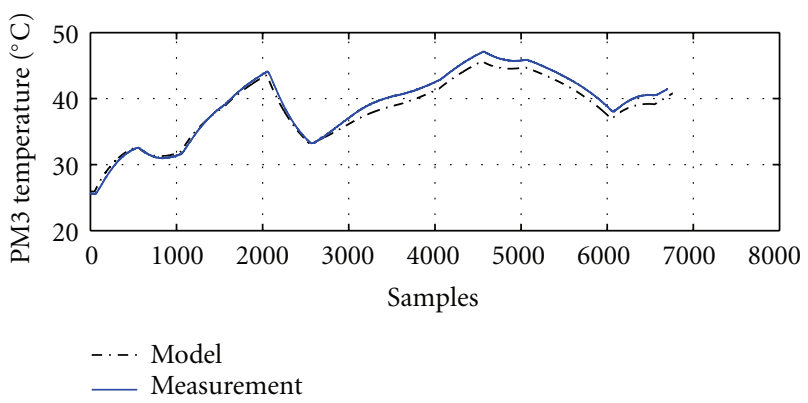

(c)

FIgURE 7: A plot of model response compared with measurements of the temperature of phase module at constant flow situation, solid line is the measurement and black dashed-dot line is the output from the simulation model, from (a)-(c) is the plot of temperature of phase module 1, 2, and 3 separately.

between inlet water temperature of the power module, outlet water temperature of the power module, inlet water temperature of the air-cooled heat exchanger, and outlet water temperature of the air-cooled heat exchanger can be expressed as

$$
\begin{aligned}
& T_{\text {fanw,out }}(t)=T_{\text {psw,in }}(t), \\
& T_{\text {fanw,in }}(t)=T_{\text {psw,out }}(t) .
\end{aligned}
$$

Through substituting (18) into (17), inserting the expression of mass flow, and rearranging the expression (17), the dynamic model of power module inlet water temperature can be described as

$$
\begin{aligned}
\dot{T}_{\mathrm{psw}, \text { in }}(t)= & \frac{q \rho}{M_{\mathrm{w}}}\left(T_{\mathrm{psw}, \text { out }}(t)-T_{\mathrm{psw}, \text { in }}(t)\right) \\
& +\frac{\lambda \cdot A}{M_{\mathrm{w}} \cdot c_{\mathrm{w}}}\left(T_{\mathrm{air}}(t)-T_{\mathrm{psw}, \text { in }}(t)\right) .
\end{aligned}
$$

After developing the three dynamic models that can be used to illustrate the energy transfer phenomena happening in the cooling system, the dynamic model of the cooling system can be summarized and expressed by using (7), (11), (12), (13), (16) and (19). A linear model is formed through using a Taylor series approximation, which is described in [27], on the finalized nonlinear model. The linearized model is subsequently discretized by using the $z$-transform as illustrated in [28] and transformed into a state-space representation with states, inputs, outputs, disturbances and noises, which can be shown as

$$
\begin{aligned}
& \mathbf{x}_{t}(n+1)=\mathbf{A}_{t} \cdot \mathbf{x}_{t}(n)+\mathbf{B}_{t} \cdot \mathbf{u}_{t}(n)+\mathbf{E}_{t} \cdot \mathbf{d}_{t}(n)+\mathbf{w}(n), \\
& \mathbf{y}_{t}(n)=\mathbf{C}_{t} \cdot \mathbf{x}_{t}(n)+\mathbf{v}(n),
\end{aligned}
$$

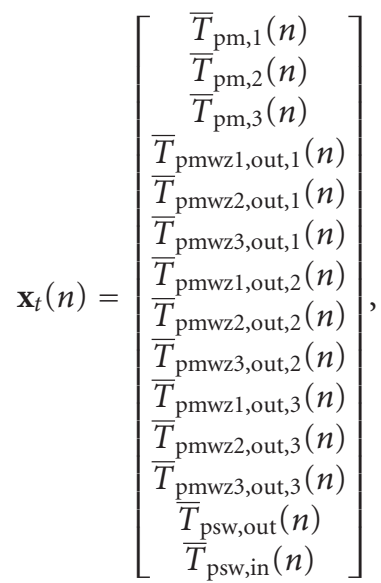

$$
\begin{aligned}
& \mathbf{u}_{t}(n)=\bar{P}_{\text {in }}(n) \text {, } \\
& \mathbf{y}_{t}(n)=\left[\begin{array}{c}
\bar{T}_{\mathrm{pm}, 1}(n) \\
\bar{T}_{\mathrm{pm}, 2}(n) \\
\bar{T}_{\mathrm{pm}, 3}(n) \\
\bar{T}_{\mathrm{psw}, \text { out }}(n) \\
\bar{T}_{\mathrm{psw}, \mathrm{in}}(n)
\end{array}\right],
\end{aligned}
$$


where a given signal $o$ is linearized by $\bar{o}=o-o_{0}, o_{\mathrm{O}}$ is the operation point of $o, \mathbf{d}_{t}(n)$ represents not only the additive disturbances, but also the modelling uncertainties due to linearization. $\mathbf{w}(n)$ is the normal distributed process disturbances, and $\mathbf{v}(n)$ is the normal distributed measurement noises. The system matrices are shown as follows:

$$
\mathbf{A}_{\mathbf{t}}=\left[\begin{array}{cccccccccccccc}
-a_{1,1} & 0 & 0 & \frac{a_{1,1}}{3} & \frac{a_{1,1}}{3} & \frac{a_{1,1}}{3} & 0 & 0 & 0 & 0 & 0 & 0 & 0 & 0 \\
0 & -a_{1,1} & 0 & 0 & 0 & 0 & \frac{a_{1,1}}{3} & \frac{a_{1,1}}{3} & \frac{a_{1,1}}{3} & 0 & 0 & 0 & 0 & 0 \\
0 & 0 & -a_{1,1} & 0 & 0 & 0 & 0 & 0 & 0 & \frac{a_{1,1}}{3} & \frac{a_{1,1}}{3} & \frac{a_{1,1}}{3} & 0 & 0 \\
a_{4,1} & 0 & 0 & a_{4,4} & 0 & 0 & 0 & 0 & 0 & 0 & 0 & 0 & 0 & a_{4,14} \\
a_{4,1} & 0 & 0 & a_{4,14} & a_{4,4} & 0 & 0 & 0 & 0 & 0 & 0 & 0 & 0 & 0 \\
a_{4,1} & 0 & 0 & 0 & a_{4,14} & a_{4,4} & 0 & 0 & 0 & 0 & 0 & 0 & 0 & 0 \\
0 & a_{4,1} & 0 & 0 & 0 & 0 & a_{4,4} & 0 & 0 & 0 & 0 & 0 & 0 & a_{4,14} \\
0 & a_{4,1} & 0 & 0 & 0 & 0 & a_{4,14} & a_{4,4} & 0 & 0 & 0 & 0 & 0 & 0 \\
0 & a_{4,1} & 0 & 0 & 0 & 0 & 0 & a_{4,14} & a_{4,4} & 0 & 0 & 0 & 0 & 0 \\
0 & 0 & a_{4,1} & 0 & 0 & 0 & 0 & 0 & 0 & a_{4,4} & 0 & 0 & 0 & a_{4,14} \\
0 & 0 & a_{4,1} & 0 & 0 & 0 & 0 & 0 & 0 & a_{4,14} & a_{4,4} & 0 & 0 & 0 \\
0 & 0 & a_{4,1} & 0 & 0 & 0 & 0 & 0 & 0 & 0 & a_{4,14} & a_{4,4} & 0 & 0 \\
0 & 0 & 0 & 0 & 0 & a_{13,6} & 0 & 0 & a_{13,6} & 0 & 0 & a_{13,6} & -3 \cdot a_{13,6} & 0 \\
0 & 0 & 0 & 0 & 0 & 0 & 0 & 0 & 0 & 0 & 0 & 0 & \frac{q \rho}{M_{\mathrm{w}}} & -\frac{q \rho \cdot c_{\mathrm{w}}+\lambda \cdot A}{M_{\mathrm{w}} \cdot c_{\mathrm{w}}}
\end{array}\right],
$$

where: $a_{1,1}=K_{\mathrm{h}} q^{0.8} A_{\mathrm{pm}, i} /\left(M_{\mathrm{pm}} \cdot c_{\mathrm{alu}}\right), a_{4,1}=\left(K_{h} q^{0.8}\right.$. $\left.A_{\mathrm{pm}, i}\right) /\left(M_{\mathrm{pmw}, \text { out }} \cdot c_{\mathrm{w}}\right), a_{4,4}=-\left(K_{h} q^{0.8} \cdot A_{\mathrm{pm}, i}+3 \cdot q \rho \cdot\right.$ $\left.c_{\mathrm{W}}\right) /\left(M_{\text {pmw,out }} \cdot c_{\mathrm{w}}\right), a_{4,14}=(3 \cdot q \rho) / M_{\text {pmw,out }}, a_{13,6}=$ $q \rho / M_{\text {psw,out }}$

$$
\begin{gathered}
\mathbf{B}_{t}=\left[\frac{1}{M_{\mathrm{pm}} \cdot c_{\mathrm{alu}}} \frac{1}{M_{\mathrm{pm}} \cdot c_{\mathrm{alu}}} \frac{1}{M_{\mathrm{pm}} \cdot c_{\mathrm{alu}}} \mathbf{0}_{1 \times 11}\right]^{T}, \\
\mathbf{C}_{t}=\left[\begin{array}{ccc}
\mathbf{I}_{3 \times 3} & \mathbf{0}_{3 \times 9} & \mathbf{0}_{3 \times 2} \\
\mathbf{0}_{2 \times 3} & \mathbf{0}_{2 \times 9} & \mathbf{I}_{2 \times 2}
\end{array}\right], \\
\mathbf{E}_{t}=\left[\begin{array}{ccc}
\mathbf{I}_{13 \times 13} & \mathbf{0}_{13 \times 1} & \mathbf{0}_{13 \times 1} \\
\mathbf{0}_{1 \times 13} & 1 & \frac{\lambda \cdot A}{M_{\mathrm{w}} \cdot c_{\mathrm{W}}}
\end{array}\right] .
\end{gathered}
$$

However, it is known that the main nonlinearities of the system are of a bilinear nature, caused in particular by the products of temperature and flow in several subsystems. As a consequence, especially close to small flows, the dynamics of the overall system change rapidly. Due to this, it can be necessary to employ a gain-scheduling approach if linear techniques such as the proposed in this paper are applied. Thus, the development in the remaining part of the paper should be seen as a design instance for one gain-scheduling cell. Due to considerations of limitation of space and brevity of exposition, a full gain-scheduling approach is not elaborated in this paper, as the design of such is rather straightforward.

2.3. Parameter Estimation and Model Validation. Some parameters in the developed dynamic model are estimated by using SENSTOOLS [29] in MATLAB. SENSTOOLS
TABLE 2: Occurrence scale of fault in liquid-cooled frequency converter.

\begin{tabular}{lcc}
\hline Probability & Failure Rate & Ranking \\
\hline Very high & $\geq 20 \%$ of faults & 4 \\
High & $10-19 \%$ of faults & 3 \\
Moderate & $4-5 \%$ of faults & 2 \\
Low & $1-2 \%$ of faults & 1 \\
\hline
\end{tabular}

uses the Gauss-Newton algorithm to minimize the squared residuals found as the difference between the data obtained by measurement on real system and calculated from a simulation model.

The parameters which needed to be estimated are $M_{\mathrm{pm}}$, $K_{\mathrm{h}}, \lambda, M_{\mathrm{w}}, M_{\mathrm{pmw}, \text { out }}$, and $M_{\mathrm{psw}, \text { out }}$. The responses of the models are compared with measurements. Figure 7 shows the comparison between the models and measurement for the temperature of phase module. Figure 8 presents the comparison between the models and measurement for the temperature of power module outlet water and inlet water. The measurement data is sampled with sample frequency at $10[\mathrm{~Hz}]$. From these plots, it can be seen that the responses from the models are quite similar to the dynamic changes as the measurements showing. Consequently, it can be concluded that the developed model can be well suited for the system behavior.

2.4. Fault Analysis. In the following, an analysis of possible faults in a liquid-cooled frequency converter is presented. The purpose of the analysis is to identify different faults and their effects on the behavior of the liquid-cooled frequency converter. The following analysis can be divided into three parts. 


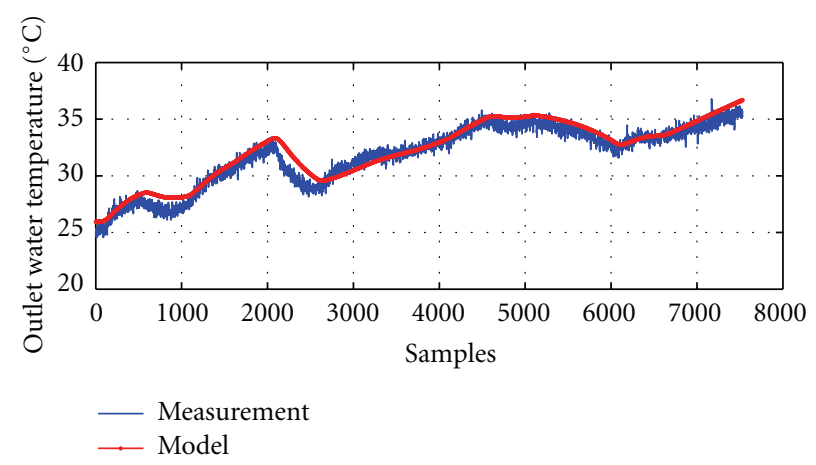

(a)

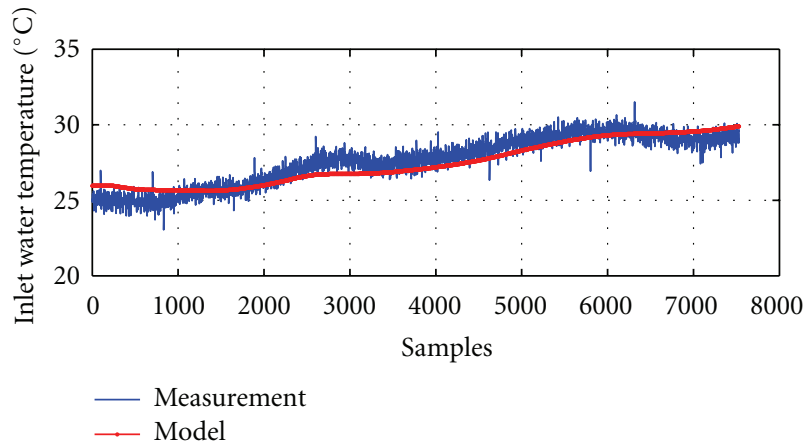

(b)

FIGURE 8: A plot of model response compared with measurements of the temperature of power module inlet and outlet water at constant flow situation, solid line is the measurements, and red dotted line is the output from the simulation model, from (a) and (b) is the temperature of power module outlet water and the temperature of power module inlet water.

(i) Fault Propagation Analysis: An analysis of the faults propagation throughout the liquid-cooled frequency converter for determining the endeffect.

(ii) Fault Assessment: An assessment of the identified faults in the fault propagation analysis for determining their occurrence and severity.

(iii) Fault Specification: An specification of the identified faults in the fault assessment analysis.

2.4.1. Fault Propagation Analysis. The failure mode and effect analysis (FMEA) is selected as a tool to make fault propagation analysis for both the cooling system unit and the power electronics unit in the liquid-cooled frequency converter. The FMEA is originally developed by reliability engineer for analyzing components in a system for possible failures, failure causes, and effects as described in [30]. By using FMEA analysis, a set of tables including information about failure modes, reasons, and effects can be achieved for the analyzed components.

The FMEA scheme for the cooling system unit is shown in Figure 9, which illustrates the fault propagation in the cooling system unit. From the analysis, it is noticed that the faults in the cooling system unit can result in a flow variation as end effect. Figure 10 is FMEA scheme for the power electronics unit, from the analysis, it can be known that the faults in the cooling system unit can propagate into the power electronics unit, which eventually can cause phase module temperature changing.

From the above FMEA analysis, it can be concluded that the end effect in the cooling system unit is a flow rate variation. Because of the flow rate variation, the cooling capacity of the phase module will be directly affected, whereas the end effect in the power electronics unit is temperature variation of the phase module.

2.4.2. Fault Assessment. A severity of end effect and occurrence analysis is considered after the FMEA analysis. The result of the fault assessment analysis is used to determine which faults should be taken into account for FDI system.
Faults are classified based on their likelihood of occurrence and severity of their end effect on scales. These can be combined in the Severity Occurrence Index (SOI), which is obtained through multiplication of the severity and occurrence values [31]. The idea of the classification is that faults with the highest SOI should be paid attention to the highest priority.

In order to carry out the occurrence and severity analysis, definitions of occurrence and severity are described firstly. Occurrence refers to the happening probability of a fault and is quantified on a scale from 1 (Low) to 4 (Very high). The occurrence scale of failure in the liquid-cooled frequency converter is defined in Table 2 with the consultation from [32]. For wind turbine industry, the statistics about the distribution of failures in Denmark, Germany, and Sweden can be found in $[33,34]$.

Severity is the potential harm effects of the faults which inflict on the system. The severity level of different faults in the liquid-cooled frequency converter is provided in Table 3 which the effect of the faults varies from 1 (None) to 9 (hazardous) according to the description in [32].

After defining the occurrence scale and severity level of the faults in the liquid-cooled frequency converter, the severity and occurrence analysis for the cooling system in the liquid-cooled frequency converter is carried out. According to the occurrence time of faults in the cooling system, the faults can be divided into two categories: startup faults and runtime faults. The startup faults refer to the faults occurring in the cooling system during the self-test phase of the liquidcooled frequency converter when it begins at startup. The runtime faults refer to the faults occurring in the cooling system during the period when wind turbine is in operation The severity and occurrence analysis result of the cooling system both at startup phase and runtime period is shown as Table 4. In this table, the value for both the severity and the occurrence of the different faults are described. The SOI is found by the value of the severity and occurrence of the faults. The priority of the different faults is determined according to the value of the SOI. 


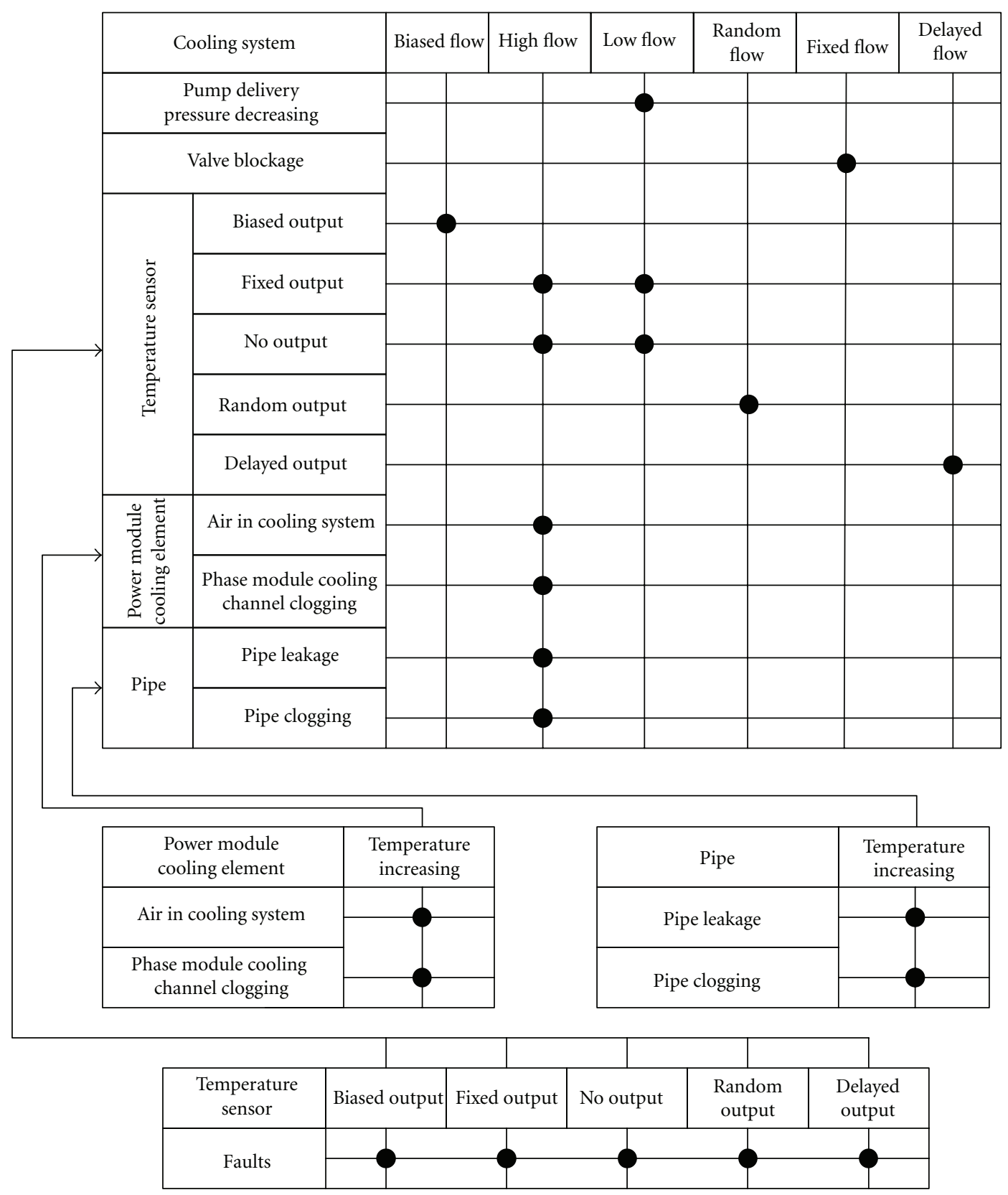

FIGURE 9: FMEA diagram of cooling system unit in liquid-cooled frequency converter.

2.4.3. Fault Specification. The purpose of the fault specification is to specify which faults will be considered according to the analysis result of fault assessment. The criterion for selection is that the faults can be artificially introduced to the test setup, so that the designed FDI algorithm can be tested. Table 5 depicts the faults that will be considered in this paper. In the paper, for startup faults, the faults that can happen in the power module cooling element are considered. The faults include air in cooling system and phase module cooling channel clogging. Air in cooling system fault means that air is present in the inlet chamber of power module. This fault can be caused by changing cooling water of the cooling system. The phase module cooling channel clogging fault refers to the cooling channels under phase module which are clogged due to solid particles in the cooling water. For runtime fault, pump delivery pressure decreasing, pipe clogging, air-cooled heat exchanger cooling effect decreasing and temperature sensor defect fault are considered. The other faults are not considered in the current research due to the hardware constraints in the test setup.

\section{Fault Detection and Isolation}

In this section, an FDI scheme is proposed and applied for detecting faults in the cooling system of the liquid-cooled frequency converter. 

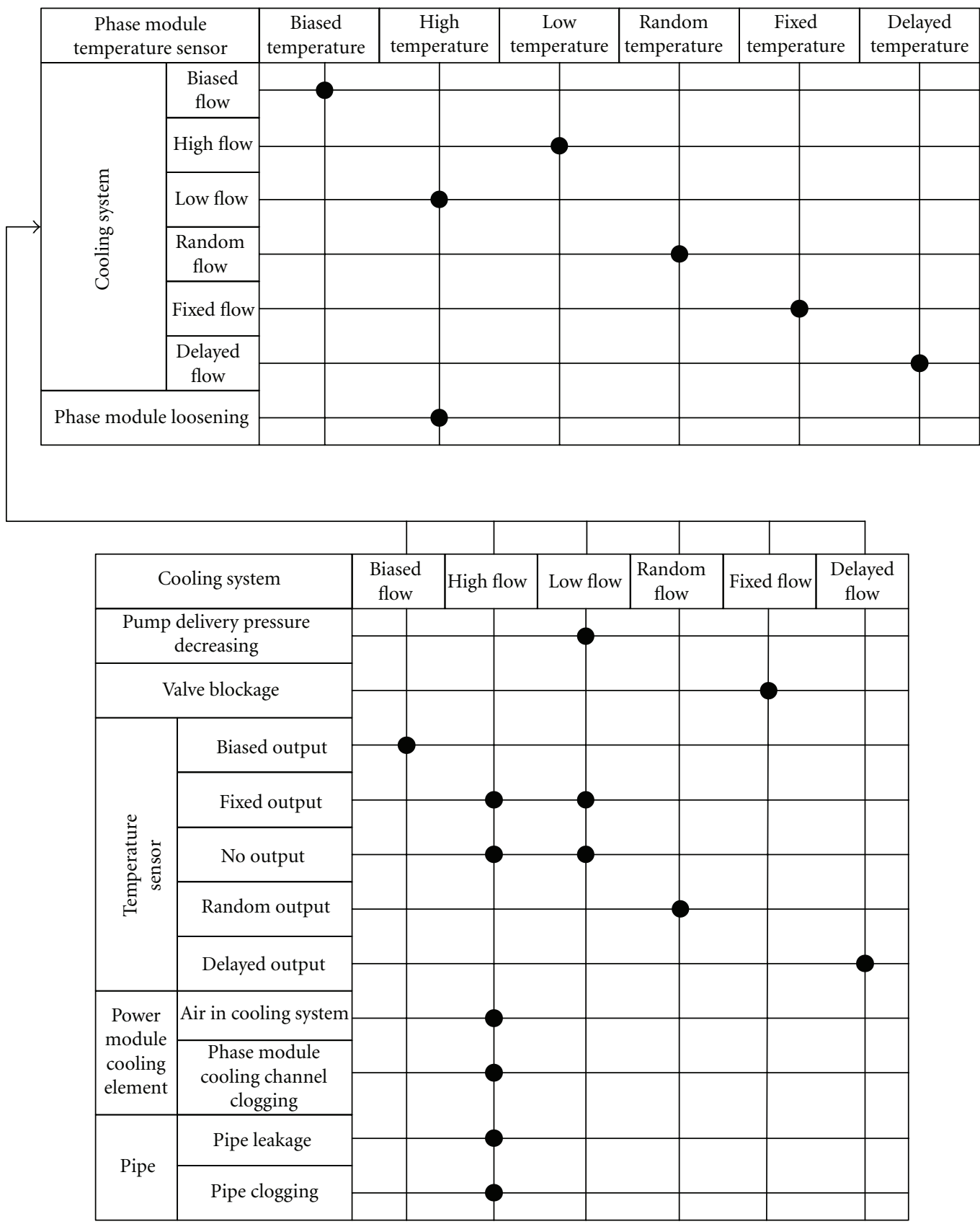

FIGURE 10: FMEA diagram of power electronic unit in liquid-cooled frequency converter.

3.1. Fault Detection. The observer scheme for detecting the faults in the cooling system is designed first. In order to detect the startup faults in the cooling system, active fault detection method is considered, and auxiliary signals for active fault detection are designed.

3.1.1. Optimal Unknown Input Observer. The optimal unknown input observer which is described in [25] is selected for designing the FDI observer. The optimal unknown input observer can be used to estimate states in the system which suffers unknown inputs and noise. Given the state-space model expression for the cooling system at discrete time state with unknown disturbances and noise as

$$
\begin{aligned}
\mathbf{x}_{t}(n+1)= & \mathbf{A}_{t} \mathbf{x}_{t}(n)+\mathbf{B}_{t} \mathbf{u}_{t}(n)+\mathbf{E}_{t} \mathbf{d}_{t}(n)+\mathbf{w}(n), \\
& \mathbf{y}_{\mathbf{t}}(n)=\mathbf{C}_{t} \mathbf{x}_{t}(n)+\mathbf{v}(n) .
\end{aligned}
$$

An optimal unknown input observer with the following form can be derived:

$$
\begin{gathered}
\mathbf{z}_{t}(n+1)=\mathbf{F}_{n+1} \mathbf{z}_{t}(n)+\mathbf{T}_{n+1} \mathbf{B}_{n} \mathbf{u}_{t}(n)+\mathbf{K}_{n+1} \mathbf{y}_{t}(k), \\
\hat{\mathbf{x}}_{t}(n+1)=\mathbf{z}_{t}(n+1)+\mathbf{H}_{n+1} \mathbf{y}_{t}(n+1) .
\end{gathered}
$$

As described in [35], the basic idea of the optimal unknown input observer is to eliminate the dependency of 


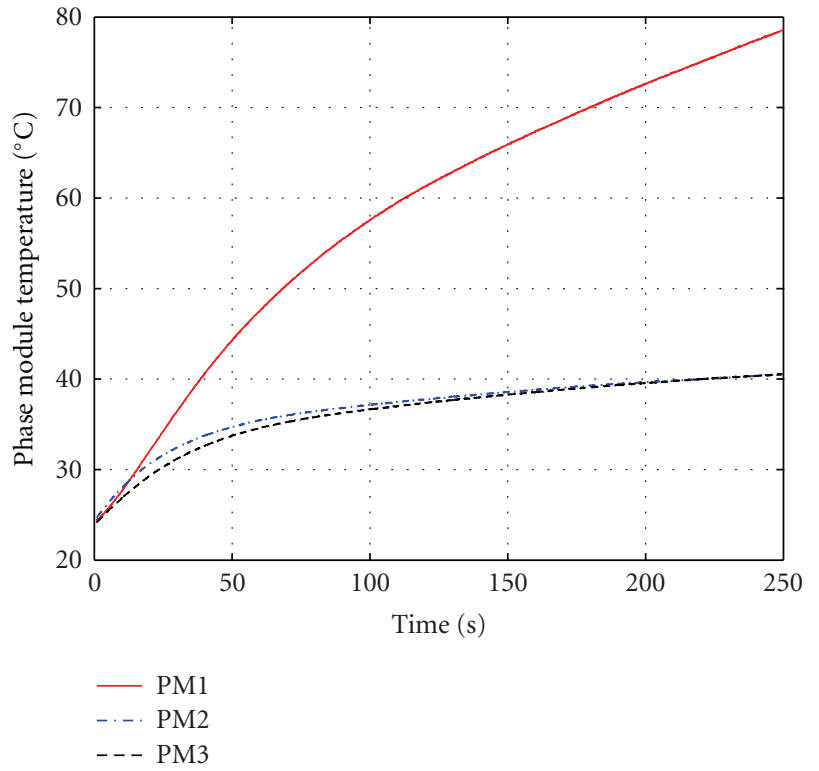

Figure 11: The variation of temperature for three phase modules during the experiment when the air in cooling system fault occurs, the fault is introduced into system from time $0[\mathrm{~s}]$.

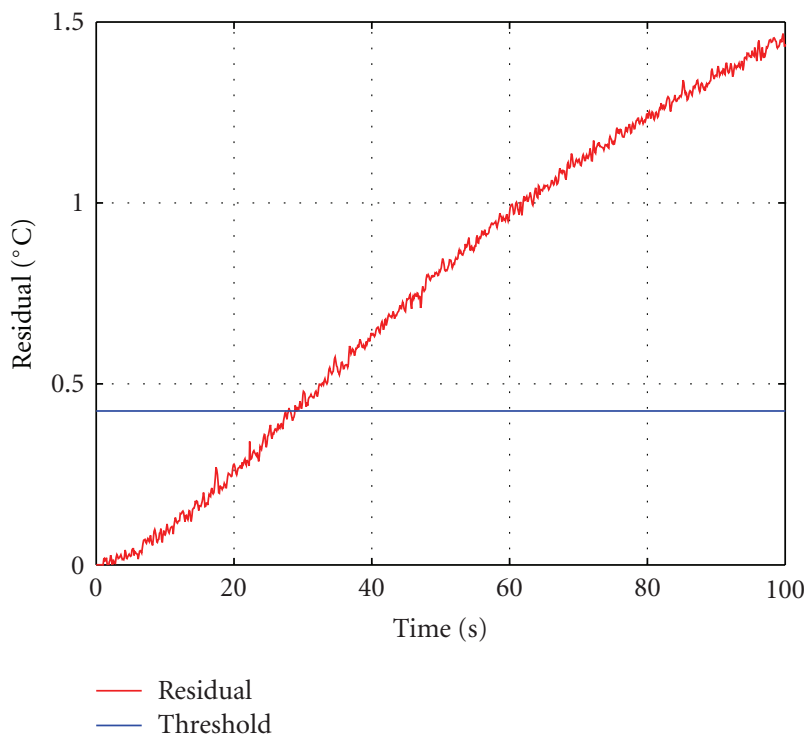

FIgURE 12: The CUSUM residual signal for air in cooling system fault, the fault is introduced at time $0[\mathrm{~s}]$ by introducing air into the cooling chamber of the top phase module, the residual overcomes the threshold value at time 30.1 [s].

the unknown input disturbance from the estimation error by matrix transforms and design a Kalman estimator for the transformed system. The advantage of using this kind of observer is that the estimator gain is recomputed at every sample time, so that the linear model matrices can be updated corresponding to current state values. The schemes for computing the matrices in the optimal unknown input observer can be seen in [25] and also can be found in the appendix.
TABLE 3: Severity level of fault in liquid-cooled frequency converter.

\begin{tabular}{|c|c|c|}
\hline Effect & Severity of effect & Ranking \\
\hline Hazardous & $\begin{array}{l}\text { The operation of system may not be safe } \\
\text { and/or not in compliance with government } \\
\text { regulations (f.x. IEC or UL standard) }\end{array}$ & 9 \\
\hline Very high & The primary functionalities are lost & 8 \\
\hline High & $\begin{array}{l}\text { The system is only operable at reduced } \\
\text { performance }\end{array}$ & 7 \\
\hline Moderate & $\begin{array}{l}\text { The overall system performance is affected } \\
\text { but the system is functional }\end{array}$ & 6 \\
\hline Low & $\begin{array}{l}\text { Minor parts of the system operating at } \\
\text { reduced performance }\end{array}$ & 5 \\
\hline Very low & $\begin{array}{l}\text { The fault is noticed but does not affect the } \\
\text { overall system performance }\end{array}$ & 4 \\
\hline Minor & $\begin{array}{l}\text { The fault is often noticed but does not } \\
\text { affect the overall system performance }\end{array}$ & 3 \\
\hline Very minor & The fault is only noticed in rare cases & 2 \\
\hline None & No noticeable effect & 1 \\
\hline
\end{tabular}

TABLE 4: Severity and occurrence analysis of faults both at startup and runtime phase in liquid-cooled frequency converter.

\begin{tabular}{|c|c|c|c|c|}
\hline $\begin{array}{l}\text { Assessment } \Rightarrow \\
\text { Fault } \Downarrow\end{array}$ & Severity & Occurrence & $\mathrm{SO}$ & Priority \\
\hline \multicolumn{5}{|c|}{ Startup faults } \\
\hline Air in cooling system & 9 & 3 & 27 & 1 \\
\hline $\begin{array}{l}\text { Phase module Cooling } \\
\text { channel clogging }\end{array}$ & 9 & 2 & 18 & 1 \\
\hline \multicolumn{5}{|c|}{ Runtime faults } \\
\hline $\begin{array}{l}\text { Pump delivery pressure } \\
\text { Decreasing }\end{array}$ & 8 & 2 & 16 & 2 \\
\hline Pipe clogging & 8 & 2 & 16 & 2 \\
\hline Pipe leakage & 8 & 2 & 16 & 2 \\
\hline $\begin{array}{l}\text { Air-cooled heat } \\
\text { Exchanger cooling effect } \\
\text { Decreasing }\end{array}$ & $6-8$ & 2 & 16 & 2 \\
\hline Valve blockage & $6-8$ & 2 & 16 & 2 \\
\hline $\begin{array}{l}\text { Temperature sensor } \\
\text { defect }\end{array}$ & 9 & 3 & 27 & 1 \\
\hline Phase model loosening & 9 & 1 & 9 & 3 \\
\hline
\end{tabular}

3.1.2. Active Fault Detection Auxiliary Signals. As specified in the section of fault specification, the faults that occur in the cooing system of the liquid-cooled frequency converter can be classified into two categories, startup faults and runtime faults. In order to detect startup faults, active fault detection approach as described in [36] is considered. The reason for using active fault detection approach for detecting startup faults is that the wind turbine is not in operation when the frequency converter is in the startup phase, the frequency converter takes self-test procedure for preparation to startup of the wind turbine.

One of the critical issues for implementing active fault detection approach is to design a "reasonable" auxiliary signal as illustrated in [36]. From the control principle and structure of the cooling system in the liquid-cooled 
TABLE 5: List of faults considered in the test setup.

\begin{tabular}{ll}
\hline Component & \multicolumn{1}{c}{ Fault type } \\
\hline Startup faults \\
\hline Power Module Cooling Element & $\begin{array}{l}\text { (1) Air in cooling system } \\
\text { (2) Phase model cooling } \\
\text { channel clogging }\end{array}$ \\
\hline Puntime faults \\
Pipe & Delivery pressure Decreasing \\
Air-cooled heat exchanger & Clogging \\
Temperature sensor & Cooling effect decreasing \\
\hline
\end{tabular}

frequency converter, it is known that there are three signals which can be controlled, input power of power module $P_{\text {total }}$, flow rate of refrigerant in the cooling system $q$, and supply voltage of fan in the air-cooled heat exchanger $V_{\text {fan }}$. Therefore, the auxiliary signals used for active fault detection will be selected from these three available signals.

Based on investigations, it is found that the temperature of phase module is affected by the two startup faults, when the flow rate in the system is set to be zero in the startup fault situation. It can be found that the thermal time constant of the top phase module (phase module 1) in the power module will decrease by comparing with the other two phase modules, when air in cooling system fault is introduced in the system by introducing air only in the top part of inlet chamber of power module. However, the thermal time constant of the top phase module (phase module 1) will keep the same value as the other two phase modules, when the phase module cooling channel clogging fault is introduced in the cooling channel of phase module 1. The reason of this phenomenon can be explained as the forced convection is between the air and aluminum plate when air in cooling system fault is presented in the system. However, the convection is between water and aluminum plate when phase module cooling channel clogging fault is presented in the system. Because the flow rate is set to be zero and the aluminum plate can only have convection with the cooling water under the aluminum plate, the thermal time constant of the three phase modules will have the same value. Consequently, the first auxiliary signal for detecting air in cooling system fault is chosen to be a flow rate of zero and a constant input power of power module at 1570 [W]. The 1570 [W] is selected based on consideration of heating capacity constraint of power module in the test setup.

As the first auxiliary signal has been determined, it is possible to detect air in cooling system fault, and the second auxiliary signal must be designed to exalt the system such that the phase module cooling channel clogging fault can be detected. From the experiment, it can be concluded that the temperature of phase module with cooling channel clogging fault will increase faster than other phase module without channel clogging fault when a power input is applied and there exists moving flow in the cooling system. Therefore, it is chosen the auxiliary signal with a flow rate of $5[\mathrm{~L} / \mathrm{min}]\left(8.33 \times 10^{-5}\left[\mathrm{~m}^{3} / \mathrm{s}\right]\right)$ and a constant power input

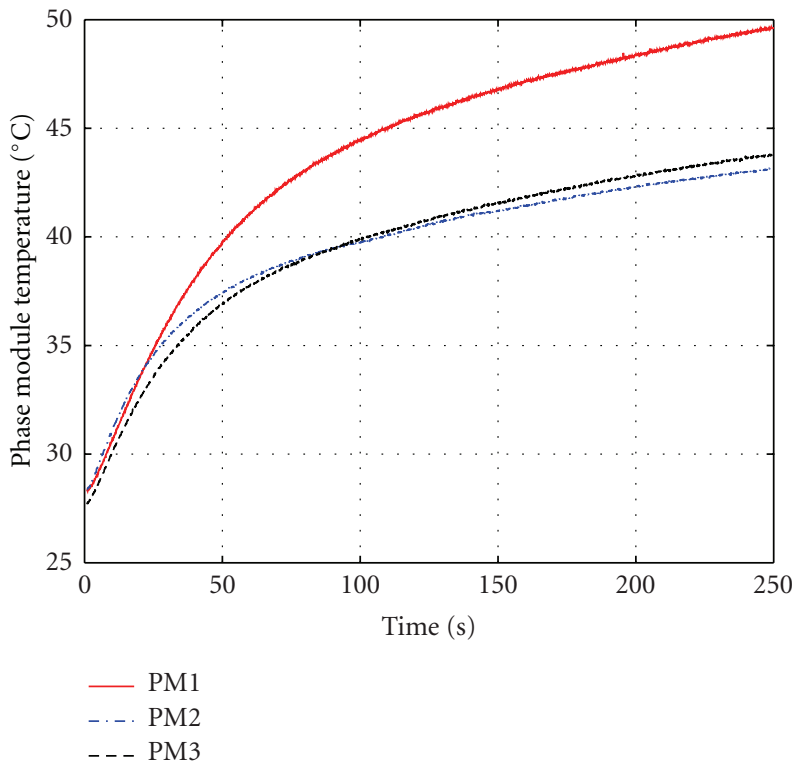

FIGURE 13: The variation of temperature for three phase modules when phase module cooling channel clog fault happens on phase module 1 , and the fault is introduced into system from time $0[\mathrm{~s}]$.

TABle 6: Auxiliary signals of active fault detection for detecting startup faults.

\begin{tabular}{lll}
\hline Fault type & Auxiliary signal & Time \\
\hline \multirow{3}{*}{ Air in cooling system } & $q=0[\mathrm{~L} / \mathrm{min}]$ or $(q=0$ & \\
& $\left.\left[\mathrm{m}^{3} / \mathrm{s}\right]\right)$ & $250 \mathrm{~s}$ \\
& $P_{\text {total }}=1570[\mathrm{~W}]$ & \\
\hline Phase module cooling & $q=5[\mathrm{~L} / \mathrm{min}]$ & \\
channel clogging & $\left(q=8.33 \times 10^{-5}\left[\mathrm{~m}^{3} / \mathrm{s}\right]\right)$ & $250 \mathrm{~s}$ \\
& $P_{\text {total }}=1570[\mathrm{~W}]$ & \\
\hline
\end{tabular}

at 1570 [W] to power module for detecting phase module cooling channel clogging fault.

Considering the testing time of the auxiliary signals for detecting two different startup faults, it is known that the frequency converter self-test can take several minutes in the wind turbine; therefore, the lasting time of the auxiliary signals can be several minutes, for example, $250 \mathrm{~s}$.

The auxiliary signals of active fault detection for different startup faults can be summarized in Table 6 .

3.2. Fault Decision. In the fault decision stage, the generated residuals are evaluated, and decision rules are applied to determine if any faults have occurred in the system. In practical situation, residuals are seldom generated perfectly robust due to parameter uncertainty, disturbance, and noise. Therefore, it is also necessary to provide robustness in the decision-making phase in order to overcome model uncertainty and unknown disturbances, reduce false alarm and minimize missing alarm.

As described in [20], there exist two residuals evaluation strategies: the statistic testing strategy and norm-based strategy. From the experiments, it was noticed that the residual signal magnitude is affected by the noise. In [37], it 


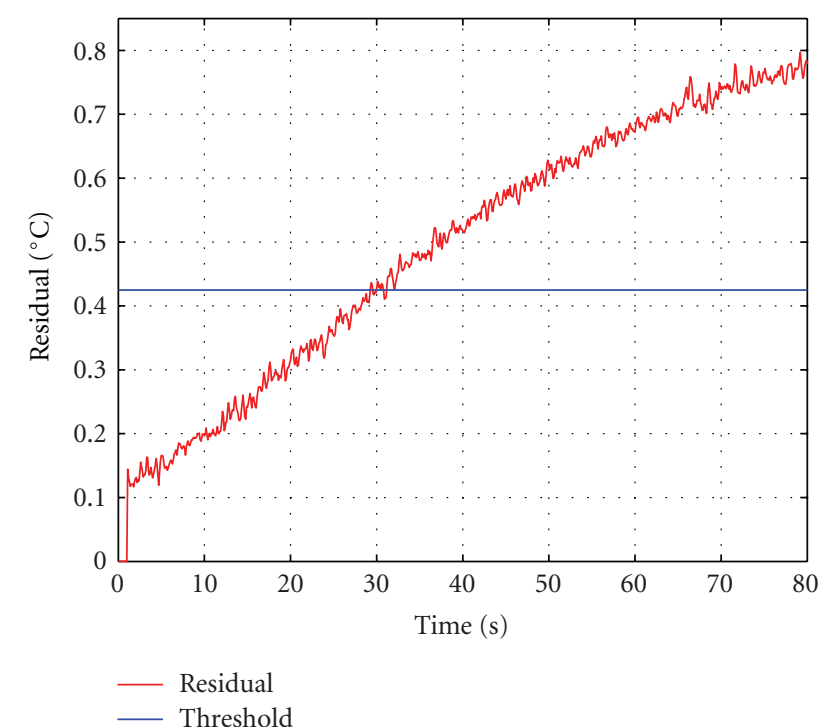

FIGURE 14: The CUSUM residual signal for detecting phase module cooling channel clogging fault. the fault is introduced at time $0[\mathrm{~s}]$ by clogging the cooling channel of phase module 1 , and the residual overcomes the threshold value at time $31.8[\mathrm{~s}]$.

is illustrated that residual evaluation is typically answerable to statistical approach because the main advantage of this approach is its ability in assessing the level of significance of the discrepancies such as noises and uncertainties. In [38], several different algorithms among the statistic testing approach are introduced, including Shewhart's chart, geometric moving average control chart (GMA), finite moving average control chart (FMA), cumulative sum (CUSUM) algorithm, and Bayes algorithm. From the former research works carried out by [37-40], it can be found that CUSUM algorithm can minimize the mean delay to detection for a given probability between false alarms [37], it can be considered as an optimal algorithm in statistical testing strategy. Therefore, the CUSUM algorithm as described in [38] is considered to evaluate the residual signal which is affected by the noise.

The CUSUM algorithm is based on the log-likelihood ratio, which can be used to measure the likelihood of two different hypotheses $H_{0}$ and $H_{1}$ which can be described by the parameter, that is $\mu$ with expression as

$$
\begin{aligned}
& H_{0} \mu=\mu_{0}, \\
& H_{1} \mu=\mu_{1} .
\end{aligned}
$$

These hypotheses can be solved by using a recursive algorithm of the following form:

$$
g_{k}= \begin{cases}g_{k-1}+\ln \frac{p_{\mu_{1}}\left(y_{k}\right)}{p_{\mu_{0}}\left(y_{k}\right)} & \text { if } g_{k-1}+\ln \frac{p_{\mu_{1}}\left(y_{k}\right)}{p_{\mu_{0}}\left(y_{k}\right)}>0, \\ 0 & \text { if } g_{k-1}+\ln \frac{p_{\mu_{1}}\left(y_{k}\right)}{p_{\mu_{0}}\left(y_{k}\right)} \leq 0,\end{cases}
$$

where $g_{0}=0$. The interpretation of the variable $g_{k}$ in the hypotheses $H_{0}$ and $H_{1}$ is given by the decision signal $f_{d}$,

$$
f_{d}= \begin{cases}1 & \text { if } g_{k} \geq r_{t} \\ 0 & \text { otherwise }\end{cases}
$$

where $r_{t}$ is a predefined threshold value.

For the purpose of evaluating the residual signal through CUSUM algorithm in the designed FDI scheme for the cooling system, it is assumed that the residual signal is normal distributed which means that the distribution of the signal can be represented as

$$
p_{\mu}(y)=\frac{1}{\sqrt{2 \pi \sigma^{2}}} e^{-(y-\mu)^{2} / 2 \sigma^{2}},
$$

where $\mu$ is the mean of the residual signal, $\sigma$ is the variance of the residual signal. Consequently, it can be deduced that $\mu=\mu_{0}$, that is, $\mu_{0}=0$, represents no fault situation, whereas $\mu=\mu_{1}$ represents fault situation. It is also assumed that the variance of the residual signal is known and does not change due to different kinds of faults, which means that the variance of the residual signal in (34) is constant and known with respect to both fault situation and fault-free situation. According to the above two assumptions, the expression for calculating log likelihood in CUSUM algorithm can be given as

$$
\ln \frac{p_{\mu_{1}}\left(y_{k}\right)}{p_{\mu_{0}}\left(y_{k}\right)}=\frac{\left(\mu_{1}-\mu_{0}\right)}{\sigma^{2}}\left(y_{k}-\frac{\mu_{1}+\mu_{0}}{2}\right) .
$$

The signal $g_{k}$ in the recursive algorithm is bounded from below by 0 and from above by $r_{t}$, which results in the following algorithm for $g_{k}$ :

$$
g_{k}= \begin{cases}0 & \text { if } g_{k-1}+\ln \frac{p_{\mu_{1}}\left(y_{k}\right)}{p_{\mu_{0}}\left(y_{k}\right)} \leq 0, \\ r_{t} & \text { if } g_{k-1}+\ln \frac{p_{\mu_{1}}\left(y_{k}\right)}{p_{\mu_{0}}\left(y_{k}\right)} \geq r_{t}, \\ g_{k-1}+\ln \frac{p_{\mu_{1}}\left(y_{k}\right)}{p_{\mu_{0}}\left(y_{k}\right)} & \text { otherwise. }\end{cases}
$$

There are different types of faults that can occur in the system as specified in Table 5, so that the residual signal of different faults will be evaluated by using different threshold values. The fault decision will be made according to the result of the residual evaluation.

3.3. Fault Isolation. The successful detection of a fault is followed by fault isolation stage, in which individual fault can be distinguished from the other faults. The purpose of fault isolation is to secure the residual set that can isolate all faults. All the faults which are considered in the current research in the cooling system can be categorized as actuator fault, process fault and sensor fault, which is depicted in Table 7. Therefore, different fault isolation methods will be considered according to the fault category in Table 7 . 


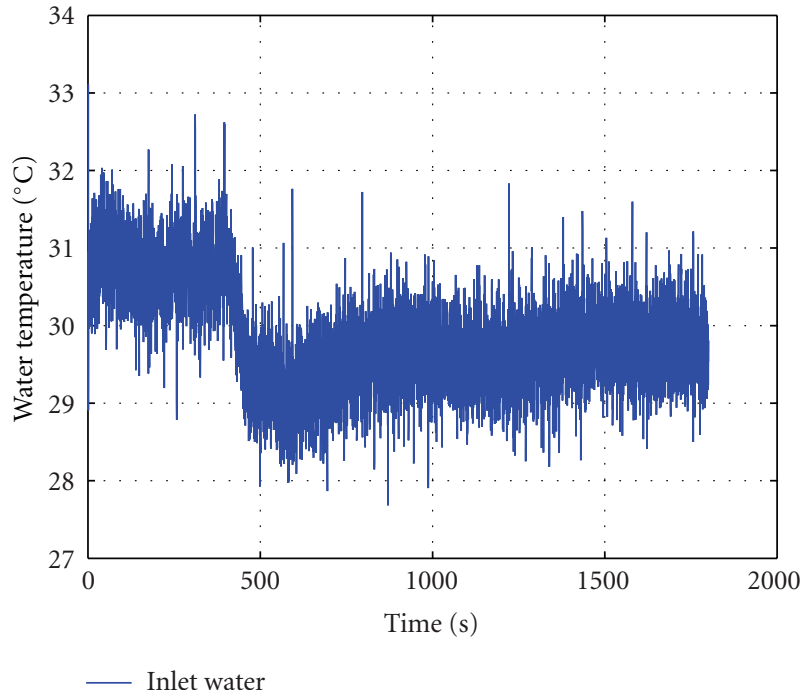

FIGURE 15: The temperature of power module inlet water during the experiment. The pump delivery pressure decreasing fault is started at time $400[\mathrm{~s}]$ by manually changing the valve position.

TABLE 7: Classes of faults in the cooling system.

\begin{tabular}{lc}
\hline Fault & Category \\
\hline \multicolumn{2}{c}{ Startup faults } \\
$\begin{array}{l}\text { Air in cooling system } \\
\text { Phase module cooling } \\
\text { Channel Clogging }\end{array}$ & Process fault \\
\hline \multicolumn{2}{c}{ Runtime faults } \\
\hline $\begin{array}{l}\text { Pump delivery pressure decreasing } \\
\text { Pipe clogging }\end{array}$ & Process fault \\
Air-cooled heat exchanger & Actuator fault \\
Cooling effect decreasing & Process fault \\
Temperature sensor defect & Actuator fault \\
\hline
\end{tabular}

3.3.1. Fault Isolation of Process Fault. The process fault in the cooling system refers to the following three faults: pipe clogging fault and two startup faults, including air in cooling system and phase module cooling channel clogging fault. Because pipe clogging fault and the two startup faults can not occur simultaneously, the pipe clogging fault and two startup faults can be easily isolated. For isolating the two startup faults, two different sets of auxiliary signals will be implemented at active fault detection approach. Therefore, the auxiliary signals and the residual signals of the FDI scheme can be used to isolate the two startup faults.

3.3.2. Fault Isolation of Actuator Fault. The actuator fault in the cooling system refers to pump delivery pressure decreasing fault and air-cooled heat exchanger cooling effect decreasing. In the current experiment, in order to obtain the maximum cooling effect, the rotation speed of the fan in the air-cooled heat exchanger will be operated at the maximum speed when there is no fault on the fan. In order to simulate the air-cooled heat exchanger cooling effect decreasing fault,

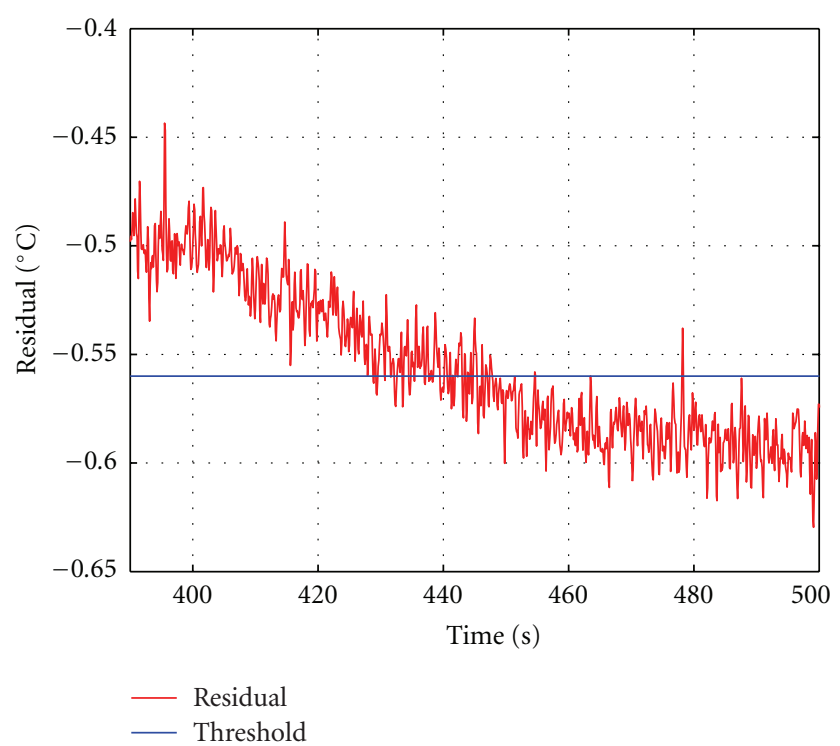

FIGURE 16: The CUSUM residual signal for detecting pump delivery pressure decreasing fault. The fault is started at time 400 [s] by manually changing the valve position, and the fault is detected at time $447: 7$ [s].

the fan speed will be operated at less than the maximum speed. From the analysis, it is founded that the pump delivery pressure decreasing fault and the air-cooled heat exchanger cooling effect decreasing fault can cause the temperature of power module inlet water to change in opposite directions. The pump delivery pressure decreasing fault can cause the temperature of power module inlet water to decrease. This can be explained as the cooling time for water in the aircooled heat exchanger is prolonged due to lower flow rate at the pump delivery pressure decreasing fault situation. For the air-cooled heat exchanger cooling effect decreasing fault, the rotation speed of the fan is reduced in the fault situation. The cooling capability of the air-cooled heat exchanger will decrease, so that the temperature of power module inlet water will increase. The residual of the temperature of power module inlet water will diverge when these two faults occur; therefore, this propriety of residual signal can be used in fault isolation stage.

3.3.3. Fault Isolation of Sensor Fault. The sensor fault in the cooling system refers to temperature sensor defect fault. In order to isolate sensor defect fault, a generalized observer scheme, which can be seen in [20], is designed for the fault isolation.

\section{Experiments and Results}

The designed FDI scheme is subsequently applied to two different groups of data, sampled at the test setup when startup faults and runtime faults are introduced. All the data are sampled with a sample frequency of $10[\mathrm{~Hz}]$. The output of the decision algorithm is binary, where a value of 1 


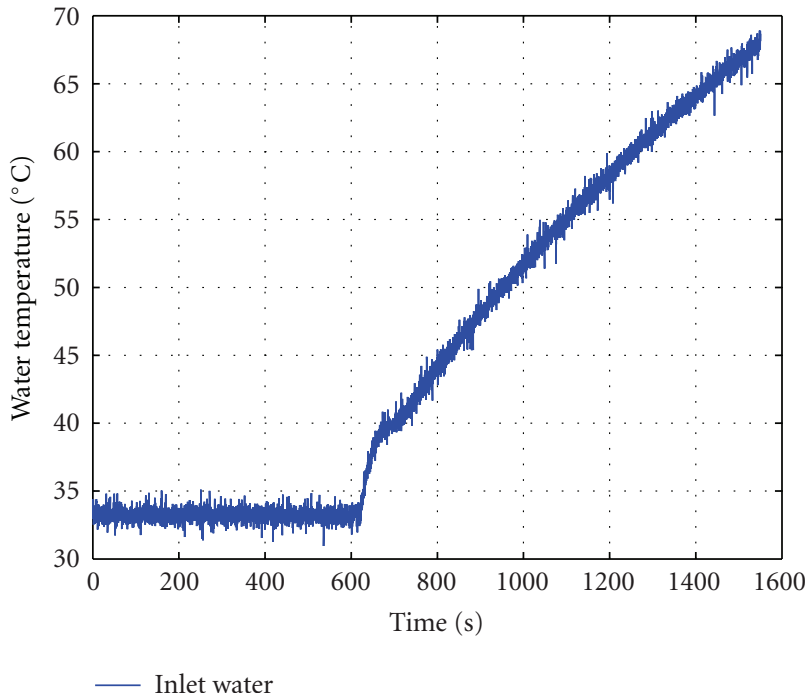

FIgURE 17: The temperature of power module inlet water during the experiment when the air-cooled heat exchanger cooling effect decreasing fault occurs, the fault is started at time $600[\mathrm{~s}]$ by changing supply voltage of the fan.

indicates that a fault has occurred and 0 indicates a fault-free operation.

4.1. Experiments and Results for Startup Faults. The first startup fault implemented on the system is air in cooling system fault. In order to introduce this fault into the system, cooling water in the cooling chamber of the top phase module (phase module 1) is removed, which means that phase module 1 will be cooled by the air instead of the water. The designed auxiliary signals for active fault detection, $q=$ $0\left[\mathrm{~m}^{3} / \mathrm{s}\right]$ and $P_{\text {total }}=1570[\mathrm{~W}]$ as described in Table 6 are applied on the test setup during the experiment.

Figure 11 shows the measurement of temperature for different phase modules during the experiment. From the figure, it is found that the temperature of phase module 1 increases faster than the other two phase modules due to there exists air in the cooling chamber of phase module 1.

The temperature of phase module 1 is used to generate residual signal for detecting the air in cooling system fault. The residual signal for this fault is shown as Figure 12. In Figure 12, the residual signal can overcome the threshold value, so that the decision can be made. The experiment concluded that the air in cooling system fault can be detected by the designed FDI scheme through using the designed auxiliary signals for active fault detection.

The next experiment is to introduce phase module cooling channel clogging fault in the test setup. The designed FDI scheme and auxiliary signals will be tested in the experiment. The cooling channel of phase module 1 is clogged in the experiment in order to simulate the fault. The auxiliary signals, $q=5[\mathrm{~L} / \mathrm{min}]\left(q=8.33 \times 10^{-5}\left[\mathrm{~m}^{3} / \mathrm{s}\right]\right)$ and $P_{\text {total }}=1570[\mathrm{~W}]$, as illustrated in Table 6 are implemented on the system. The temperature variation of different phase modules during the experiment is shown in Figure 13. From

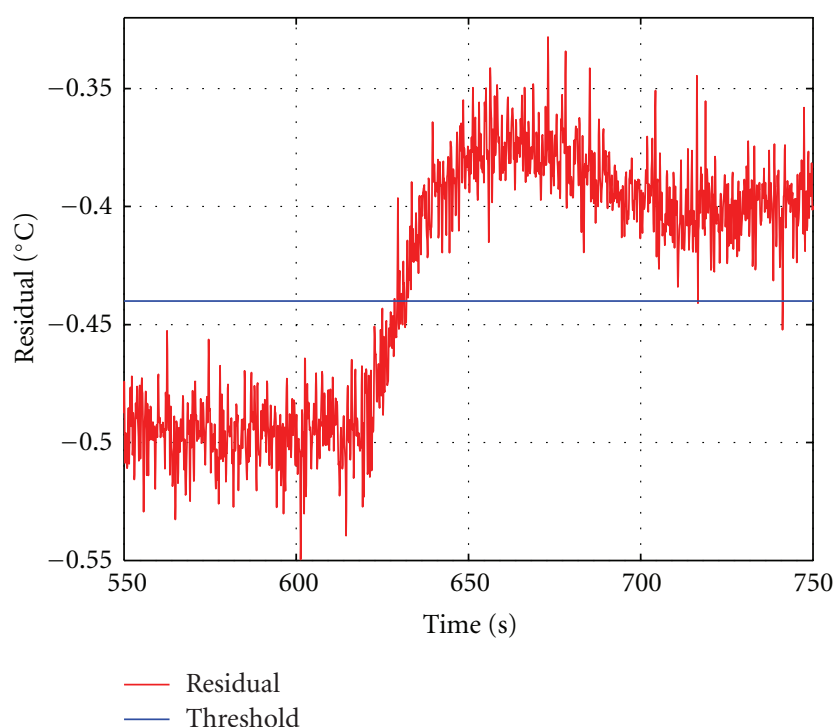

FIGURE 18: The CUSUM residual signal for detecting air-cooled heat exchanger cooling effect decreasing fault, the fault is started at time $600[s]$ by changing the supply voltage of the fan, and the fault is detected at time $632.5[s]$.

the figure, it can be seen that the temperature of phase module 1 increases significantly faster than the other two phase modules when phase module cooling channel clogging fault happens in the phase module 1.

The temperature of phase module 1 is used to generate residual signal. The residual signal for detecting phase module cooling channel clogging fault is shown as Figure 14. From the result of the experiment, it is known that the phase module cooling channel clogging fault can be detected through using the designed FDI scheme and active fault detection auxiliary signal when the fault occurs.

From the above two experiments, it can be concluded that two startup faults can be detected by using the designed FDI scheme and active fault detection auxiliary signals. The following experiments are to test the FDI scheme for detecting runtime faults when they happen in the test setup.

4.2. Experiments and Results for Runtime Faults. In the following experiments: different runtime faults are implemented on the test setup of cooling system individually. The input power of power module is set to a constant value as 1570 [W].

The first runtime fault implemented on the system is the pump delivery pressure decreasing fault. In order to introduce this fault, the flow rate in the cooling system is reduced compared with the nominal flow rate in faultfree situation by setting the valve opening position. The temperature of power module inlet water is shown as Figure 15 during the experiment. From Figure 15, it is known that the temperature of power module inlet water will decrease when the fault happens. The residual signal from the FDI scheme is illustrated in Figure 16.

From the result of the experiment, it is known that the pump delivery pressure decreasing fault can be detected by 


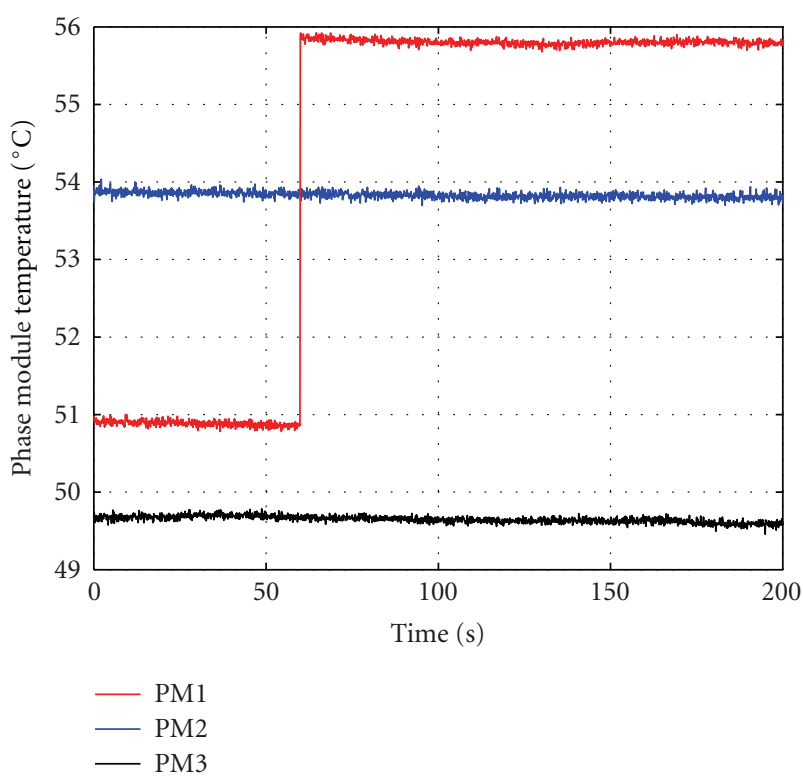

Figure 19: The measurement value of phase module temperature from phase module temperature sensor. The temperature sensor of phase module 2 is defected from time $60[s]$, and the fault is sensor bias fault.

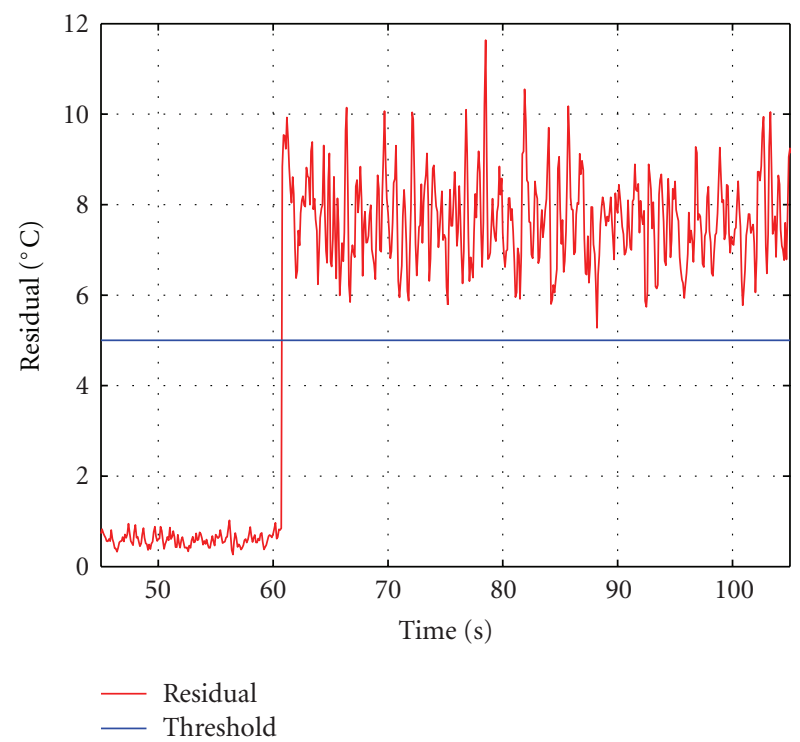

FIgURE 20: The CUSUM residual signal for detecting sensor bias fault the fault is started at time $60[s]$, and the fault is detected at time $60.8[s]$.

using the designed FDI scheme. Because of the hardware limitation in the test setup, the same valve is used to implement pipe clogging fault and pump delivery pressure decreasing fault, the pump delivery pressure decreasing fault and pipe clogging fault cannot be introduced separately. However, from the above experiment, it can be concluded that the pipe clogging fault can also be detected by using the same FDI scheme as detecting pump delivery pressure decreasing fault in the test setup.
The second runtime fault presented in the experiment is the air-cooled heat exchanger cooling effect decreasing fault. This fault can lead to a degradation of the cooling effect of the air-cooled heat exchanger. For introducing this fault into test setup, the rotation speed of the fan is reduced. The supply voltage to the fan is reduced $66 \%$ comparing with nominal supply voltage, which results in a decrease in the rotation speed of the fan. The temperature of power module inlet water during the experiment is shown in Figure 17. It is found that the temperature of power module inlet water will increase when the fault happens in the test setup. The residual signal of the FDI scheme is shown in Figure 18. From the result of the experiment, it is known that the air-cooled heat exchanger cooling effect decreasing fault can be detected by using the designed FDI scheme.

The third runtime fault implemented on the test setup is the temperature sensor defect fault. Sensor bias fault is considered currently for the cooling system since this kind of fault is one of the typical faults that can occur on the sensor. It is chosen only to show the result of introducing the bias fault on the temperature sensor of phase module 2 since the conclusions for the other sensors are identical. A bias fault at $+5^{\circ}$ is introduced to the temperature measurements in phase module 2 in a period of $60 \mathrm{~s}$. Figure 19 shows the temperature sensor output for different phase modules during the experiment. Figure 20 illustrates the residual signal for temperature sensor of phase module 2 when a bias fault occurs on it since $60 \mathrm{~s}$. From the result of the experiment, it can be concluded that temperature sensor with bias fault can be detected by using the designed FDI scheme.

From the results of the above experiments, it can be concluded that pump delivery pressure decreasing fault, pipe clogging fault, air-cooled heat exchanger cooling effect decreasing fault and temperature sensor defect fault can be detected. The summary of fault detection time for different faults in the cooling system is shown in Table 8 . From the results shown in Table 8, it is known that the detection delay time for the startup faults, air in cooling system and phase module cooling channel clogging are $30.1 \mathrm{~s}$ and $31.8 \mathrm{~s}$ separately. With the consideration of wind turbine application, the detection delay times for these two startup faults are acceptable since wind turbine normally will use several minutes to take self-test before it begins to operate. As illustrated in Table 8, the detection delay times for the runtime faults, pump delivery pressure decreasing, pipe clogging and air-cooled heat exchanger cooling effect decreasing are $47.7 \mathrm{~s}, 47.7 \mathrm{~s}$ and $32.5 \mathrm{~s}$ for each of them. From the industrial application viewpoint, the detection delay time for these three runtime faults are acceptable. However, it is preferable to have a shorter detection delay time for these three faults since the temperature of the phase module can increase rapidly during the detection delay time, and the high temperature may finally destroy the phase module. For temperature sensor with bias output fault, the detection delay time is $0.8 \mathrm{~s}$ as shown in Table 8 . The detection delay time for this kind of fault is acceptable for implementing in wind turbine industry. 
TABLE 8: List of fault detection time for different faults in the cooling system.

\begin{tabular}{|c|c|}
\hline Fault & Detection time [s] \\
\hline \multicolumn{2}{|c|}{ Startup faults } \\
\hline Air in cooling system & 30.1 \\
\hline $\begin{array}{l}\text { Phase module cooling } \\
\text { channel clogging }\end{array}$ & 31.8 \\
\hline \multicolumn{2}{|c|}{ Runtime faults } \\
\hline Pump delivery pressure decreasing & 47.7 \\
\hline pipe clogging & 47.7 \\
\hline $\begin{array}{l}\text { Air-cooled heat exchanger } \\
\text { Cooling effect decreasing }\end{array}$ & 32.5 \\
\hline Temperature sensor - bias output & 0.8 \\
\hline
\end{tabular}

For the operating points chosen in the experiments performed, the deviations between the underlying nonlinear model and the linearization were significant but not extreme. It turned out that the optimal filters designed based on the linearization of the nonlinear model achieved diagnostic results close to the anticipated quality with very little tuning. It was not attempted to do a formal quantification of the model discrepancies between the nonlinear model and its linearization although this could definitely be done without larger challenges. However, in the authors' opinion, a full industrial solution to the problem at hand should be based on a gain-scheduling approach, where the scheduling grid could always be chosen to circumvent false alarms caused by linearization errors. The nonlinear model is based on standard assumptions, which in addition to the specific verifications done in the present projects have been reported to lead to high-fidelity models for systems of this type in several other studies.

With the consideration of the fault isolation issue in the different runtime faults. It can be concluded that the fault isolation between the pump delivery pressure decreasing fault and air-cooled heat exchanger cooling effect decreasing fault can be fulfilled. However, due to the current hardware constraints of the test setup, it is not possible to isolate between pump delivery pressure decreasing fault and pipe clogging fault.

\section{Conclusion and Future Works}

5.1. Conclusion. In this paper an observer-based method for detection and isolation of faults in a liquid-cooled wind turbine frequency converter is presented. The variables for monitoring the power module cooling system in the liquid-cooled frequency converter are the temperatures of phase modules, the temperature of power module inlet water and the temperature of power module outlet water. The existing control system in the liquid-cooled frequency converter provides a measurement of these variables in order to supervise the state of the cooling system. However, the measurement of these temperatures is significantly affected by the unknown disturbances, such as ambient temperature inside of wind turbine and measurement noise. This paper suggests a method where these variables are estimated by using an optimal unknown input observer based on simple energy balance model of the cooling system in the liquidcooled frequency converter. Moreover, a fault residual evaluation scheme by using CUSUM algorithm is suggested. The designed observer is applied to startup faults and runtime faults situations on test setup where faults can occur in the same situation in the wind turbine. From the experiments it can be concluded that the fault can be detected as soon as it emerges.

5.2. Future Works. In order to investigate the advantages and disadvantages of the proposed model-based fault detection strategy in the present research work, a nonlinear fault detection scheme will be considered in the future. The possible nonlinear fault detection schemes can be, for example, high-gain observer which was illustrated in [41] and geometric approach method which was presented in [42]. In addition, in order to accommodate different faults that have been found by the proposed FDI scheme in the current research work, a fault accommodation scheme will be considered in the future work.

\section{Appendix}

Computational procedure for optimal unknown input observer algorithm and covariance matrices.

A necessary and sufficient condition for the existing of a solution to the given observer problem given in [25] is stated as an optimal unknown input observer solution exists if and only if $\operatorname{rank}\left(\mathbf{E}_{n}\right)=\operatorname{rank}\left(\mathbf{C}_{n+1} \mathbf{E}_{n}\right)$.

The computation of algorithm and the matrices in the observer are also given in [25] as the following.

(1) Set initial values: $P_{0}=P(0), \mathbf{z}_{0}=\mathbf{x}_{0}-\mathbf{C}_{0} \mathbf{E}_{0}\left(\mathbf{C}_{0} \mathbf{E}_{0}\right)^{+} \mathbf{y}_{0}$, $\mathbf{H}_{0}=0$

(2) Compute $\mathbf{H}_{n+1}=\mathbf{E}_{n}\left(\mathbf{C}_{n+1} \mathbf{E}_{n}\right)^{+}$

(3) Compute $\mathbf{K}_{n+1}^{1}=\mathbf{A}_{n+1}^{1} \mathbf{P}_{n} \mathbf{C}_{n}^{T}\left(\mathbf{C}_{n} \mathbf{P}_{n} \mathbf{C}_{n}^{T}+\mathbf{R}_{n}\right)^{-1}$, and $\mathbf{P}_{n+1}^{\prime}=\mathbf{P}_{n}-\mathbf{K}_{n+1}^{1} \mathbf{C}_{n} \mathbf{P}_{n}\left(\mathbf{A}_{n+1}^{1}\right)^{T}$

(4) Compute $\mathbf{T}_{n+1}=\mathbf{I}-\mathbf{H}_{n+1} \mathbf{C}_{n+1}, \mathbf{F}_{n+1}=\mathbf{H}_{n+1} \mathbf{C}_{n+1} \mathbf{A}_{n}-$ $\mathbf{K}_{n+1}^{1} \mathbf{C}_{n}, \mathbf{K}_{n+1}^{2}=\mathbf{F}_{n+1} \mathbf{H}_{n}$, and $\mathbf{K}_{n+1}=\mathbf{K}_{n+1}^{1}+\mathbf{K}_{n+1}^{2}$

(5) Compute $\mathbf{z}[n+1]=\mathbf{F}_{n+1} \mathbf{z}[n]+\mathbf{T}_{n+1} \mathbf{B}_{u}[n]+\mathbf{K}_{n+1} \mathbf{Y}[n]$ and $\hat{\mathbf{x}}[n+1]=\mathbf{z}[n+1]+\mathbf{H}_{n+1} \mathbf{y}[n+1]$

(6) Compute $\mathbf{P}_{n+1}^{\prime}=\mathbf{P}_{n}-\mathbf{K}_{n+1}^{1} \mathbf{C}_{n} \mathbf{P}_{n}\left(\mathbf{A}_{n+1}^{1}\right)^{T}$, and following $\mathbf{P}_{n+1}=\mathbf{A}_{n+1}^{1} \mathbf{P}_{n+1}^{\prime}\left(\mathbf{A}_{n+1}^{1}\right)^{T}+\mathbf{T}_{n+1} \mathbf{Q}_{n} \mathbf{T}_{n+1}^{T}+$ $\mathbf{H}_{n+1} \mathbf{R}_{n+1} \mathbf{H}_{n+1}^{T}$

(7) Set $n=n+1$ and jump to step (2).

\section{Nomenclature}

\section{A: $\quad$ Surface area}

$A_{\mathrm{pm}, i}:$ Surface area of phase module $i$ 
$A_{1}$ : $\quad$ Surface area of zone 1 of each phase module

$A_{2}$ : $\quad$ Surface area of zone 2 of each phase module

$A_{3}$ : $\quad$ Surface area of zone 3 of each phase module

C: $\quad$ Specific heat capacity

D: $\quad$ Hydraulic diameter

$\Delta \dot{E}_{\mathrm{pm}, i}: \quad$ Changing rate of energy in phase module $i$

$\dot{E}_{\mathrm{pm}, \mathrm{in}, i}: \quad$ Rate of energy entering phase module $i$

$\dot{E}_{\mathrm{pm}, \text { out }, i}: \quad$ Rate of energy leaving phase module $i$

$K_{\mathrm{h}}: \quad$ Transfer coefficient

$M_{\mathrm{pm}}$ : $\quad$ Mass of aluminum plate in phase module

$M_{\text {pmw,out }}$ Mass of water in phase module cooling channel

$M_{\text {pmwzl,out }}$ : Mass of water in zone 1 of cooling channel in each phase module

$M_{\text {pmwz2,out }}$ : Mass of water in zone 2 of cooling channel in each phase module

$M_{\text {pmwz3,out }}$ : Mass of water in zone 3 of cooling channel in each phase module

$M_{\text {psw,out }}$ Mass of water at outlet of power module

$M_{\mathrm{w}}$ : $\quad$ Mass of water in air-cooled heat exchanger

$P_{\text {in }}$ : Input power of phase module

$P_{\text {total }}: \quad$ Input power of power module

$Q: \quad$ Added heat energy

$T_{\text {air }}$ : Air temperature

$T_{\text {fanw,in: }}$ Inlet water temperature of air-cooled heat exchanger

$T_{\text {fanw,out }}$ Outlet water temperature of air-cooled heat exchanger

$T_{\mathrm{pm}, i}: \quad$ Temperature of phase module $i$

$T_{\text {pmw,in }}$ : Inlet water temperature of phase module cooling channel

$T_{\text {pmw,out }}$ : Outlet water temperature of phase module cooling channel

$T_{\text {pmwz1,out }, i}$ : Water temperature for zone 1 of phase module $i$

$T_{\text {pmwz2,out }, i}$ : Water temperature for zone 2 of phase module $i$

$T_{\text {pmwz3,out, } i}$ : Water temperature for zone 3 of phase module $i$

$T_{\text {psw,in: }} \quad$ Water temperature at inlet of power module

$T_{\text {psw,out }}$ Water temperature at outlet of power module

$T_{\mathrm{w}, i}: \quad$ Water temperature under phase module $i$

$V_{\text {fan }}$ : Supply voltage of fan in the air-cooled heat exhanger

$c_{\text {alu }}$ : $\quad$ Specific heat capacity of aluminum

$c_{\mathrm{W}}: \quad$ Specific heat capacity of water

$h: \quad$ Heat transfer coefficient

$m_{\text {fanw,in: }}$ Inlet mass flow of air-cooled heat exchanger

$m_{\text {fanw,out }}$ Outlet mass flow of air-cooled heat exchanger

$m_{\mathrm{pm} \text {,in: }} \quad$ Inlet mass flow of phase module cooling channel

$m_{\mathrm{pm}, \text { out }}$ : Outlet mass flow of phase module cooling channel

$m_{\mathrm{ps}, \text { in }, i}$ : Inlet mass flow of power module from phase module $i$

$m_{\mathrm{ps}, \text { out }}$ : Outlet mass flow of power module

$q$ : $\quad$ Flow rate of refrigerant in the cooling system $\rho$ : Density of fluid

$\lambda$ : A heat conductivity coefficient.

\section{References}

[1] "Global wind 2009 report," Tech. Rep., Global Wind Energy Council, 2010, http://www.gwec.net.

[2] X. Wei, M. Verhaegen, and T. van den Engelen, "Sensor fault diagnosis of wind turbines for fault tolerant," in Proceedings of the 17th World Congress The International Federation of Automatic Control, vol. 17, pp. 3222-3227, IFAC, Seoul, South Korea, 2008.

[3] P. F. Odgaard, J. Stoustrup, R. Nielsen, and C. Damgaard, "Observer based detection of sensor faults in wind turbines," in Proceedings of the European Wind Energy Conference (EWEA'09), Marseille, France, 2009.

[4] P. F. Odgaard, J. Stoustrup, and M. Kinnaert, "Fault tolerant control of wind turbines - a benchmark model," in Proceedings of the 7th IFAC Symposium on Fault Detection, Supervision and Safety of Technical Processes, pp. 155-160, Barcelona, Spain, 2009.

[5] K. Rothenhagen and F. W. Fuchs, "Current sensor fault detection and reconfiguration for a doubly fed induction generator," in Proceedings of the 38th Annual Power Electronics Specialists Conference (PESC'07), F. W. Fuchs, Ed., pp. 27322738, Orlando, Fla, USA, June 2007.

[6] K. Rothenhagen, S. Thomsen, and F. W. Fuchs, "Voltage sensor fault detection and reconfiguration for a doubly fed induction generator," in Proceedings of the IEEE International Symposium on Diagnostics for Electric Machines, Power Electronics and Drives, (SDEMPED'07), S. Thomsen, Ed., pp. 377-382, Cracow, Poland, 2007.

[7] S. Karimi, A. Gaillard, P. Poure, and S. Saadate, "FPGAbased real-time power converter failure diagnosis for wind energy conversion systems," IEEE Transactions on Industrial Electronics, vol. 55, no. 12, pp. 4299-4308, 2008.

[8] P. Poure, P. Weber, D. Theilliol, and S. Saadate, "Fault-tolerant power electronic converters: reliability analysis of active power filter," in Proceedings of the IEEE International Symposium on Industrial Electronics (ISIE '07), pp. 3174-3179, Vigo, Spain, June 2007.

[9] B. Rodrigo, N. Felipe, C. Aldo, and P. Rodrigo, "Expert fault detection and diagnosis for the refrigeration process of a hydraulic power plant," in Proceedings of the 27th Chinese Control Conference (CCC'08), pp. 122-126, Yunnan, China, 2008.

[10] A. Wichman and J. E. Braun, "Fault detection and diagnostics for commercial coolers and freezers," HVAC and R Research, vol. 15, no. 1, pp. 77-99, 2009.

[11] H. T. Grimmelius, J. Klein Woud, and G. Been, "On-line failure diagnosis for compression refrigeration plants," International Journal of Refrigeration, vol. 18, no. 1, pp. 31-41, 1995.

[12] S. Wang and J. Cui, "Sensor-fault detection, diagnosis and estimation for centrifugal chiller systems using principalcomponent analysis method," Applied Energy, vol. 82, no. 3, pp. 197-213, 2005.

[13] J. Cui and S. Wang, "A model-based online fault detection and diagnosis strategy for centrifugal chiller systems," International Journal of Thermal Sciences, vol. 44, no. 10, pp. 986-999, 2005.

[14] P. M. Frank, "Fault diagnosis in dynamic systems using analytical and knowledge-based redundancy. A survey and 
some new results," Automatica, vol. 26, no. 3, pp. 459-474, 1990.

[15] R. J. Patton, "Fault detection and diagnosis in aerospace systems using analytical redudency," IEE Comnputing \& Control Engineering Journal, vol. 2, no. 3, pp. 127-136, 1990.

[16] R. J. Patton, P. M. Frank, and R. N. Clark, Fault Diagnosis in Dynamic System Theory and Application, Prentice Hall, 1989.

[17] R. J. Patton and J. Chen, "A review of parity space approaches to fault diagnosis," in Proceedings of the IFAC/IMACS Symposium (SAFEPROCESS'91), pp. 239-255, 1991.

[18] J. Gertler, "Analytical redudency methods in failure detection and isolation," in Proceedings of the IFAC/IMACS Symposium (SAFEPROCESS'91), pp. 9-21, 1991.

[19] R. Isermann, Fault-Diagnosis Systems - An Introduction from Fault Detection to Fault Tolerance, Springer, Berlin, Germany, 2006.

[20] S. X. Ding, Model-Based Fault Diagnosis Techniques: Design Schemes, Algorithms and Tools, Springer, Berlin, Germany, 2008.

[21] P. M. Frank and J. Wünnenberg, Fault Diagnosis in Dynamic System Theory and Application, Prentice-Hall, 1989.

[22] J. Chen and H. Zhang, "Robust detection of faulty actuators via unknown input observers," International Journal of Systems Science, vol. 22, no. 10, pp. 1829-1839, 1991.

[23] R. J. Patton, J. Chen, and H. Y Zhang, "Modelling methods for improving robustness in fault diagnosis of jet engine system," in Proceedings of the 31st IEEE Conference on Decision and Control, pp. 2330-2335, Tuscon, Tex, USA, 1992.

[24] R. J. Patton, H. Y. Zhang, and J. Chen, "Modelling of uncertainties for robust fault diagnosis," in Proceedings of the 31st IEEE Conference on Decision and Control, pp. 921-926, Tuscon, Tex, USA, 1992.

[25] J. Chen and R. J. Patton, "Optimal filtering and robust fault diagnosis of stochastic systems with unknown disturbances," Control Theory and Applications, vol. 143, no. 1, pp. 31-36, 1996.

[26] Y. Cengel and R. Turner, Fundamentals of Thermal-Fluid Sciences, McGraw-Hill, 2008.

[27] B. W. Bequette, Process Control: Modeling, Design, and Simulation, Prentice-Hall, 1st edition, 2003.

[28] G. F. Franklin, J. D. Powell, and M. L. Workman, Digital Control of Dynamic Systems, Addison Wesley, 3rd edition, 1997.

[29] M. Knudsen, "Experimental modelling of dynamic systems," Tech. Rep., Department of Control Engineering, Aalborg University, 2004, www.control.aau.dk/ mk/ExpMod/ Publicdoc/LectureNote02pdf.pdf.

[30] M. Blanke, "Consistent design of dependable control systems," Control Engineering Practice, vol. 4, no. 9, pp. 1305-1312, 1996.

[31] R. Izadi-Zamanabadi and J. A. Larsen, "A fault tolerant control supervisory system development procedure for small satellites-the AAUSAT-II case," in Proceedings of the 17th IFAC Symposium on Automatic Control in Aerospace, vol. 17, pp. 289-294, Toulouse, France, 2007.

[32] W. G. Ireson, C. F. Coombs, and R. Y. Moss, Eds., Handbook of Reliability Engineering and Management, McGraw-Hill, 1996.

[33] J. Ribrant, Reliability performance and maintenance-a survey of failures in wind power systems, M.S. thesis, KTH School of Electrical Engineering, 2006, https://eeweb01.ee.kth.se/ upload/publications/reports/2006/XR-EE-EEK_2006_009.pdf.

[34] DOWEC, "Estimation of turbine reliability figures within the dowec project," Tech. Rep., Energy research Centre of the Netherlands, 2002, http://www.ecn.nl/fileadmin/ecn/ ecn/units/wind/docs/dowec/10048_004.pdf.
[35] P. F. Odgaard and B. Mataji, "Observer-based fault detection and moisture estimating in coal mills," Control Engineering Practice, vol. 16, no. 8, pp. 909-921, 2008.

[36] S. L. Campbell and R. Nikoukhah, Auxiliary Signal Design for Failure Detection, Princeton University, 2004.

[37] M. Basseville, "Model-based statistical signal processing and decision theoreic approaches to monitoring," in Proceedings of the 5th IFAC Symposium om Fault Detection, Supervision and Safety of Technical Process, pp. 1-12, Washington, DC, USA, 2003.

[38] M. Basseville and I. V. Nikiforov, Detection of Abrupt Changes-Theory and Application, Prentice-Hall, 1993.

[39] S. W. Roberts, "A comparison of some control chart procedures," Technometrics, vol. 8, pp. 411-430, 1966.

[40] B. Basseville, M. Espiau, and J. Gasnier, "EDGE detection using sequential methods for change in level -part i: a sequential edge detection algorithm," IEEE Transactions on Acoustics, Speech, and Signal Processing, vol. ASSP-29, no. 1, pp. 24-31, 1981.

[41] H. Hammouri, M. Kinnaert, and E. H. El Yaagoubi, "Observer-based approach to fault detection and isolation for nonlinear systems," IEEE Transactions on Automatic Control, vol. 44, no. 10, pp. 1879-1884, 1999.

[42] C. De Persis and A. Isidori, "A geometric approach to nonlinear fault detection and isolation," IEEE Transactions on Automatic Control, vol. 46, no. 6, pp. 853-865, 2001. 

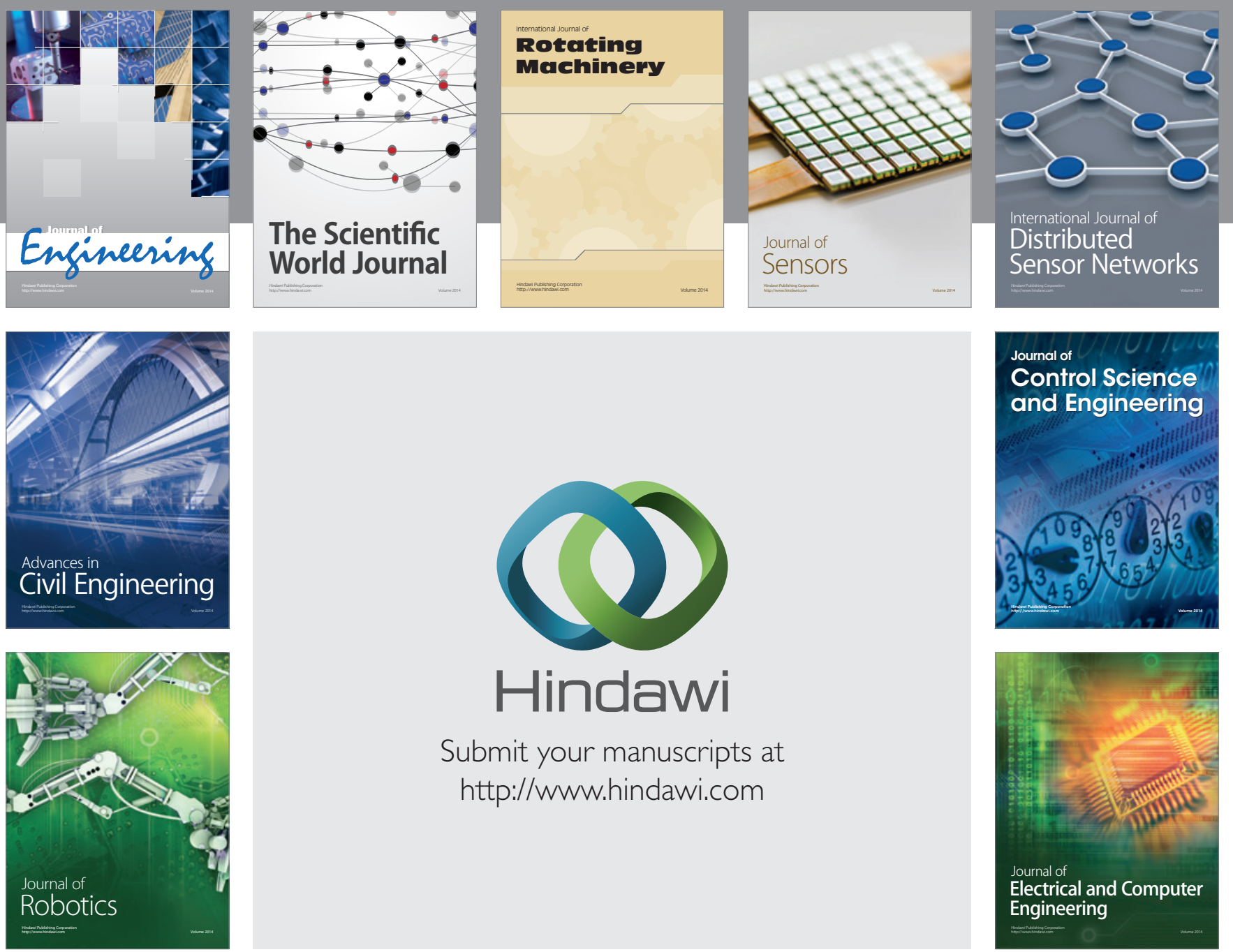

Submit your manuscripts at

http://www.hindawi.com
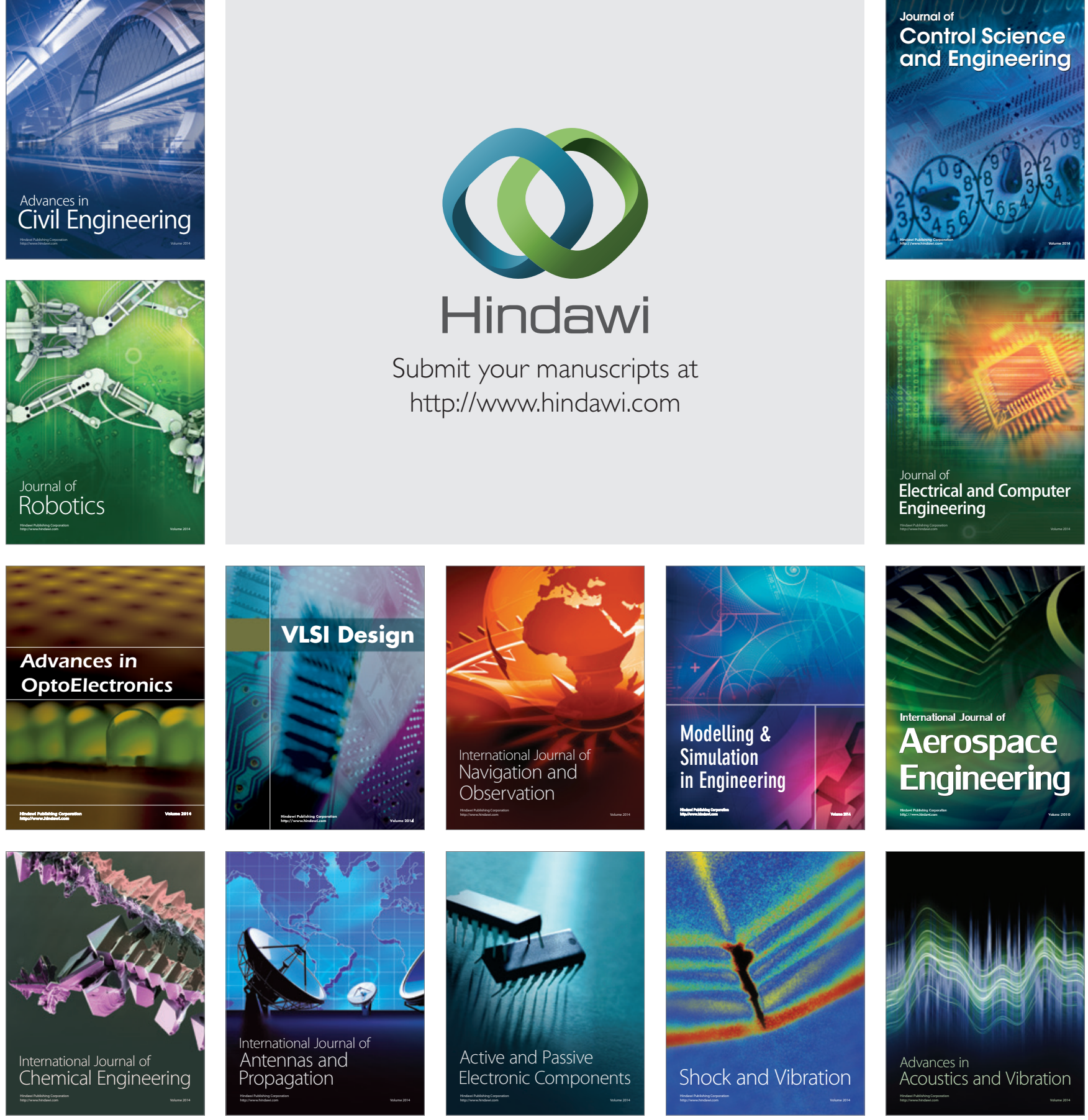